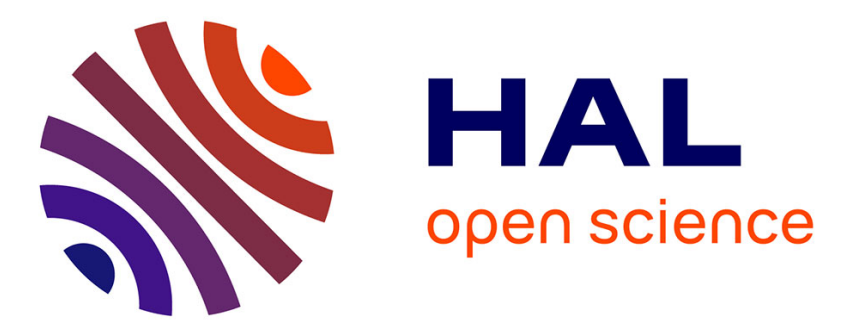

\title{
Microvilli-derived extracellular vesicles carry Hedgehog morphogenic signals for Drosophila wing imaginal disc development
}

Ilse Hurbain, Anne-Sophie Macé, Maryse Romao, Elodie Prince, Lucie Sengmanivong, Laurent Ruel, Renata Basto, Pascal Thérond, Graça Raposo, Gisela D'angelo

\section{To cite this version:}

Ilse Hurbain, Anne-Sophie Macé, Maryse Romao, Elodie Prince, Lucie Sengmanivong, et al.. Microvilli-derived extracellular vesicles carry Hedgehog morphogenic signals for Drosophila wing imaginal disc development. Current Biology - CB, 2021, 10.1016/j.cub.2021.11.023 . hal-03481430

\author{
HAL Id: hal-03481430 \\ https://hal.science/hal-03481430
}

Submitted on 4 Jan 2022

HAL is a multi-disciplinary open access archive for the deposit and dissemination of scientific research documents, whether they are published or not. The documents may come from teaching and research institutions in France or abroad, or from public or private research centers.
L'archive ouverte pluridisciplinaire HAL, est destinée au dépôt et à la diffusion de documents scientifiques de niveau recherche, publiés ou non, émanant des établissements d'enseignement et de recherche français ou étrangers, des laboratoires publics ou privés. 


\section{Current Biology}

Microvilli-derived extracellular vesicles carry Hedgehog morphogenic signals for Drosophila wing imaginal disc development

\section{Highlights}

- PromL is a key determinant of microvilli formation in the wing disc epithelium

- The integrity of microvilli is critical for the biogenesis of EVs

- Microvilli-derived EVs ferry $\mathrm{Hh}$ and PromL from Hh-producing to Hh-recipient cells

- Microvilli-derived EVs mediate Hh long-range signaling in the wing imaginal disc

\section{Authors}

Ilse Hurbain, Anne-Sophie Macé, Maryse Romao, ..., Pascal P. Thérond, Graça Raposo, Gisela D’Angelo

\section{Correspondence}

gisela.dangelo@curie.fr

\section{In brief}

Hurbain et al. highlight a novel aspect of Hedgehog secretion route in the Drosophila wing imaginal disc epithelium. They combine fluorescence and electron microscopy with genetic approaches to unveil that microvilli are an important source of small extracellular vesicles that mediate the long-range effect of the morphogen Hedgehog. 


\title{
Current Biology
}

\section{Microvilli-derived extracellular vesicles carry Hedgehog morphogenic signals for Drosophila wing imaginal disc development}

\author{
Ilse Hurbain, ${ }^{1,2}$ Anne-Sophie Macé, ${ }^{1,2}$ Maryse Romao, ${ }^{1,2}$ Elodie Prince, ${ }^{3}$ Lucie Sengmanivong, ${ }^{1,2}$ Laurent Ruel, ${ }^{3}$ \\ Renata Basto, ${ }^{1}$ Pascal P. Thérond, ${ }^{3}$ Graça Raposo, ${ }^{1,2}$ and Gisela D'Angelo ${ }^{1,2,4, *}$ \\ ${ }^{1}$ Institut Curie, PSL Research University, CNRS, UMR144, 26 rue d'Ulm, 75248 Paris Cedex 05, France \\ 2Institut Curie, PSL Research University, CNRS, UMR144, Cell and Tissue Imaging Facility (PICT-IBiSA), 26, rue d'UIm, 75248 Paris Cedex 05, \\ France \\ 3Université Côte d'Azur, UMR7277 CNRS, Inserm U1091, Institute of Biology Valrose (iBV), Parc Valrose, 06108 Nice Cedex 2, France \\ ${ }^{4}$ Lead contact \\ ${ }^{*}$ Correspondence: gisela.dangelo@curie.fr \\ https://doi.org/10.1016/j.cub.2021.11.023
}

\section{SUMMARY}

Morphogens are secreted molecules that regulate and coordinate major developmental processes, such as cell differentiation and tissue morphogenesis. Depending on the mechanisms of secretion and the nature of their carriers, morphogens act at short and long range. We investigated the paradigmatic long-range activity of Hedgehog $(\mathrm{Hh})$, a well-known morphogen, and its contribution to the growth and patterning of the Drosophila wing imaginal disc. Extracellular vesicles (EVs) contribute to Hh long-range activity; however, the nature, the site, and the mechanisms underlying the biogenesis of these vesicular carriers remain unknown. Here, through the analysis of mutants and a series of Drosophila RNAi-depleted wing imaginal discs using fluorescence and live-imaging electron microscopy, including tomography and 3D reconstruction, we demonstrate that microvilli of the wing imaginal disc epithelium are the site of generation of small EVs that transport Hh across the tissue. Further, we show that the Prominin-like (PromL) protein is critical for microvilli integrity. Together with actin cytoskeleton and membrane phospholipids, PromL maintains microvilli architecture that is essential to promote its secretory function. Importantly, the distribution of $\mathrm{Hh}$ to microvilli and its release via these EVs contribute to the proper morphogenesis of the wing imaginal disc. Our results demonstrate that microvilli-derived EVs are carriers for Hh long-range signaling in vivo. By establishing that members of the Prominin protein family are key determinants of microvilli formation and integrity, our findings support the view that microvilli-derived EVs conveying Hh may provide a means for exchanging signaling cues of high significance in tissue development and cancer.

\section{INTRODUCTION}

Hedgehog $(\mathrm{Hh})$ is a well-known morphogen acting at short and at long range to control tissue patterning as well as cell growth and differentiation during embryonic development. ${ }^{1}$ The effects of $\mathrm{Hh}$ are well exemplified in the Drosophila wing imaginal discs that give rise to the adult wings. The wing imaginal disc is subdivided into anterior $(A)$ and posterior $(P)$ compartments, with different molecular and cellular identities. Hh is exclusively produced in $P$ cells and signals across the A/P compartment boundary to induce the expression of short- (i.e., engrailed [En] and Patched [Ptc]) and long-range (i.e., decapentaplegic [dpp]) target genes in A recipient cells.

The secretion of $\mathrm{Hh}$ involves dual lipid modifications, consisting in the addition of a cholesterol moiety at the $\mathrm{C}$ terminus and a palmitic acid at the $\mathrm{N}$ terminus of the mature protein., ${ }^{2,3}$ These lipid modifications that firmly anchor $\mathrm{Hh}$ to the membrane lipid bilayer are nevertheless essential for the morphogenetic signaling activity of $\mathrm{Hh}$. Given this lipid anchorage, several studies have addressed the question as to how $\mathrm{Hh}$ is released from producing cells to elicit its long-range activity at a distance up to $50 \mu \mathrm{m}$ in A recipient cells. These last few years, different modes of carrier-mediated $\mathrm{Hh}$ long-range signaling have been proposed, ${ }^{1}$ including extracellular vesicles (EVs), that arise either from the fusion of multivesicular body (MVB) with the plasma membrane (exosomes) or from budding of the plasma membrane (ectosomes or microvesicles). ${ }^{1,4}$ Evidences have been provided to suggest that both types of EVs, whose nature is tightly dependent on the site of Hh secretion (basolateral secretion for the former ${ }^{5}$ and apical secretion for the other ${ }^{6,7}$ ) could mediate $\mathrm{Hh}$ long-range activity in Drosophila epithelia. $^{8-10}$ They could act either via their release into the extracellular space, mostly from the apical surface of the cells, or via their transport along cytonemes (thin filopodia-like protrusions) ${ }^{11}$ that transiently form at the basal plane of the wing disc epithelium. ${ }^{5,9,12,13}$ Whether the long-range signaling of $\mathrm{Hh}$ depends on its apical or basolateral secretion or on both remains a matter of debate..$^{5-7,9,14}$ 
A

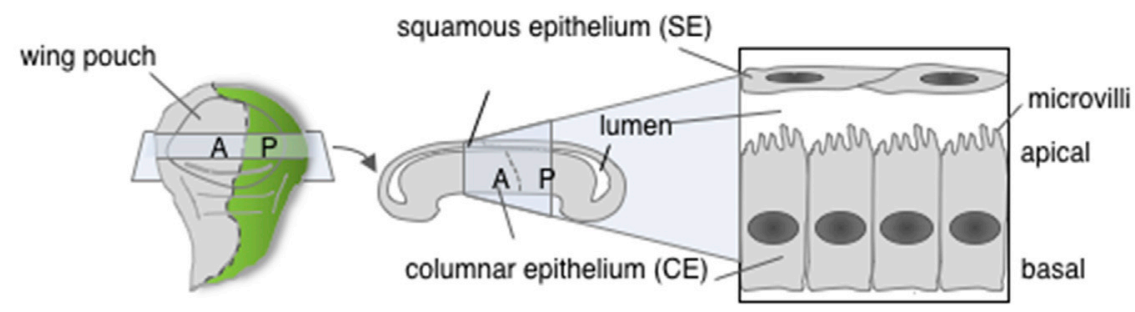

B

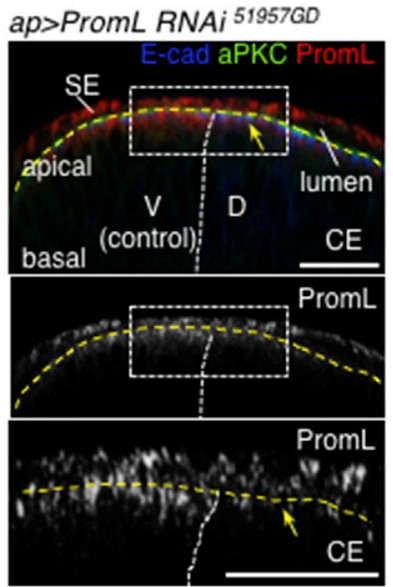

E $w t$

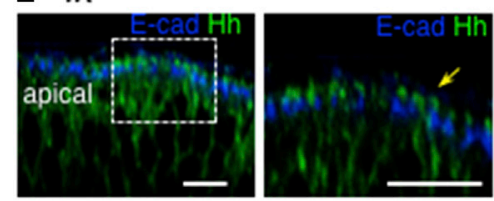

F $\operatorname{promL}^{43-1}$

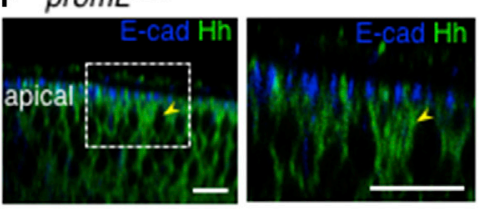

G $h$ h>promL2xsgRNA

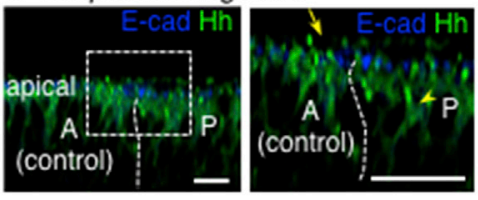

H hh>PromL RNAi $51957 G 0$

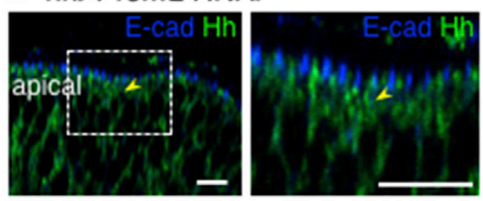

C
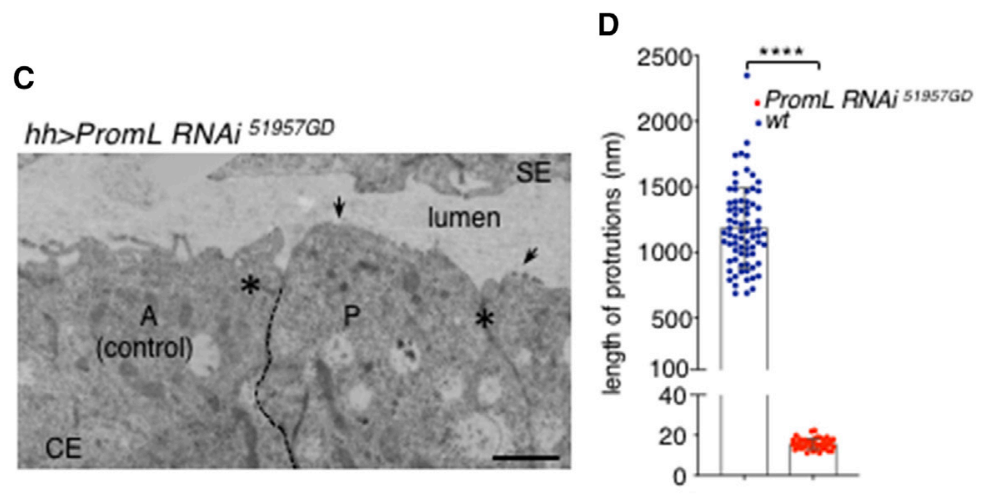

I $h$ h $>$ PromL RNAi $51957 G 0$
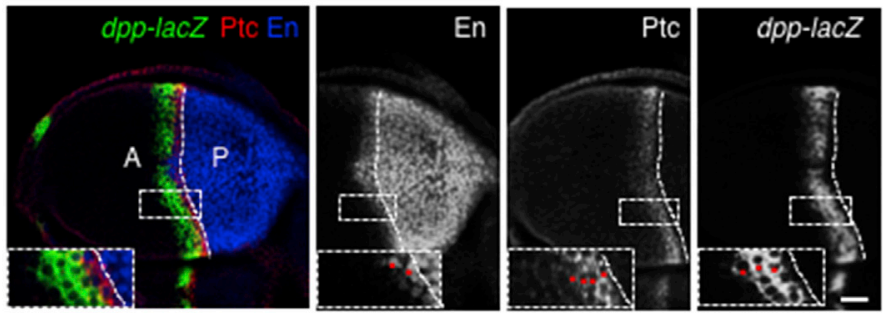

$\mathbf{J} w t$
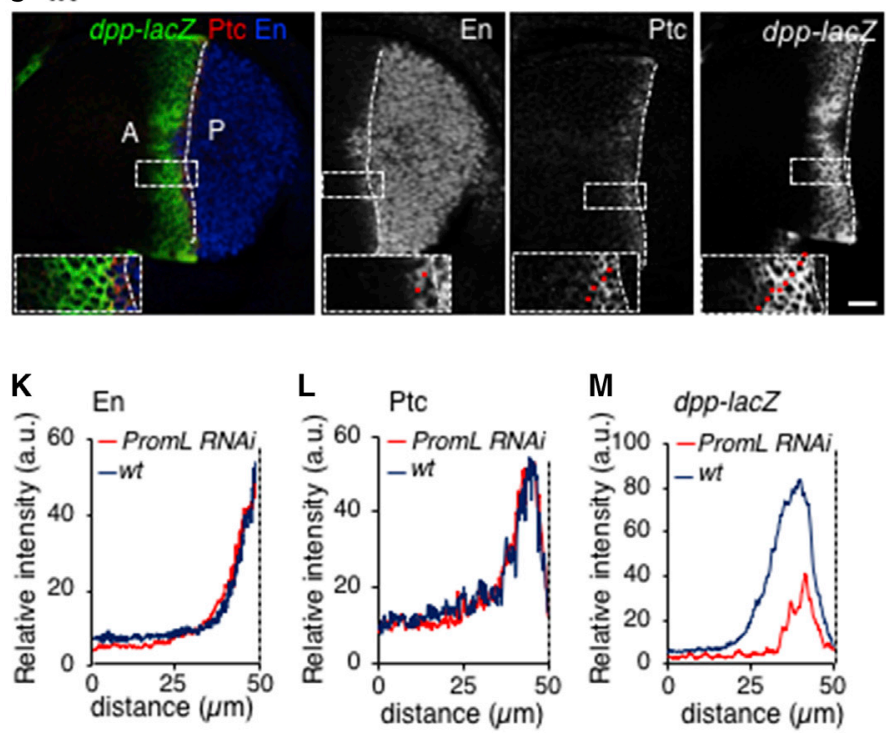

Figure 1. Hh long-range activity relies on microvilli integrity

(A) Schematic of the larval wing imaginal disc epithelium and a transverse section. The disc is oriented anterior (A) to the left, posterior (P) to the right. The wing imaginal disc consists of two layers of cells with apical surfaces facing each other: the columnar epithelium (CE) of the wing disc pouch overlayered by the squamous epithelium (SE), separated by the extracellular space (lumen). Microvilli cover the apical surface of the wing imaginal disc. 


\section{Current Biology Article}

The apical membrane of epithelial cells is enriched in cholesterol, glycosphingolipids, and PiP2 ${ }^{15-18}$ and characterized by the presence of microvilli that have been shown to give rise to EVs. ${ }^{19,20}$ Among the molecular components associated to EVs, members of the Pentaspan Prominin protein family are of particular interest. In mammals, the direct binding of prominin-1 to membrane cholesterol determines its specific retention to microvilli, ${ }^{21,22}$ and the cholesterol content regulates the microvilli morphology as well as the budding and fission of prominin-1containing EVs. ${ }^{20}$ However, our understanding of the mechanisms of microvilli-EV biogenesis and its potential contribution to intercellular communication during development is presently unclear.

To examine the relationship between microvilli, EV biogenesis, and their potential significance, we investigated the origin of EVs, the molecular mechanisms underlying their biogenesis, and their function in Hh long-range signaling during development by using the epithelium of the Drosophila wing imaginal disc as an experimental model. By loss- and gain-of-function experiments, we showed that PromL protein is crucial for both the maintenance of microvilli architecture and the generation of EVs in epithelial cells of the wing imaginal disc. Not unlike PromL, $\mathrm{Hh}$ is addressed to microvilli and secreted associated to EVs, as shown by fluorescence, live imaging, electron microscopy, and tomography. Finally, the loss of PromL and other proteins interacting with the actin cytoskeleton and phospholipids of the plasma membrane impaired the distribution of $\mathrm{Hh}$ to microvilli and $\mathrm{EV}$ secretion, compromising therefore $\mathrm{Hh}$ long-range signaling in the A recipient cells. Based on these findings, we propose that microvilli-derived EVs contribute to Hedgehog long-range signaling activity, highlighting their physiological importance in tissue development in vivo.

\section{RESULTS}

PromL distributes to microvilli of the wing imaginal disc epithelium

We tested whether the sorting of $\mathrm{Hh}$ to microvilli and their ability to generate EVs could be prerequisites for the deployment of $\mathrm{Hh}$ long-range signaling in the Drosophila wing imaginal disc (Figure $1 \mathrm{~A}$ ). To investigate the formation of microvilli-derived EVs, we monitored the PromL protein that has been reported, upon overexpression, to distribute to apical protrusions of Drosophila wing imaginal discs. ${ }^{23}$ To validate the newly generated antibodies raised against the PromL protein (this study; STAR Methods; Figure S1A), we analyzed the subcellular distribution of the corresponding immunoreactivity in the dorsal (D) wing disc compartment expressing GFP-tagged PromL ${ }^{23}$ driven by the apterous-Gal4 driver (ap>PromL-GFP) and compared it to the ventral (V) wild-type (WT) compartment within the same discs.

Endogenous PromL immunolabeling massively colocalized with PromL-GFP and distributed at the uppermost apical surface of the cells above E-cadherin (E-cad) (a subapical marker; Figure S1B). In contrast, PromL was not detected at the basolateral side where PromL-GFP was previously observed. ${ }^{23}$ It did not overlap with GFP-tagged Viking (GFP-Vkg) (a collagen IV type molecule that labels the basement membrane), ${ }^{24}$ but instead, it colocalized with Cad99c, a specific marker of microvilli of wing imaginal disc and ovarian follicle epithelial cells (this study; Figures S1B-S1D). ${ }^{25,26}$ The strong Cad99c expression in the dorsal compartment might result from an effect of overexpressed PromL-GFP on the distribution and/or stability of Cad99c. In addition, a substantial reduction of PromL immunolabeling was detected in the conditional promL2xsgRNA (this study; STAR Methods) or in promL ${ }^{4}{ }^{3-1}$ mutant wing discs, ${ }^{27}$ further evidencing the specificity of the PromL antibodies (Figures S1E-S1J). Overall, these results show that PromL is associated with the apical compartment of epithelial wing disc cells, consistent with an association and distribution to microvilli, and excluded from the basal plane of the wing disc epithelium.

\section{PromL is required for the maintenance of microvilli architecture and integrity}

Next, we functionally tested the impact of PromL protein on microvilli architecture and integrity through knockdown using RNA interference (RNAi) driven by ap > or hedgehog-Gal4 ( $h$ h $>$ ) to target $\mathrm{D}$ or $\mathrm{P}$ cells, respectively, and in the two promL mutants. We found that, in all these genetic backgrounds, PromL signal was specifically abrogated (Figures 1B, S1E, S1G, S1I, S1J, S2A, and S2D; compare to WT compartment in Figures 1B, S1G, S2A, and S2D). However, cell polarity (as revealed by aPKC, E-cad, and Dlg staining-apical, subapical, and basolateral markers, respectively) was not perturbed and apoptosis levels were not increased (as revealed by caspase III staining), indicating an absence of tissue stress in such conditions (Figures

(B and E-J) Single confocal sections of discs of the indicated genotypes stained for PromL (red; white), aPKC (green), E-cad (blue), Hh (green), En (blue; white), Ptc (red; white), and $\beta$-gal (reflecting the expression of the reporter gene $d p p$-lacZ; green; white).

(B) Transverse confocal sections of wing discs depleted for PromL in the dorsal (D) compartment. Yellow arrows mark the substantial decrease of PromL signal in the $\mathrm{D}$ compartment as compared to the $\mathrm{V}$ control compartment within the same disc. Yellow broken line delineates the apical surface. Brightness and contrast have been increased for a better visualization of the overall PromL signal (lowest panel).

(C) TEM of $h h>$ PromL RNA $i^{51957 G D}$ wing disc showing the absence of microvilli in PromL-depleted P compartment (arrows). Asterisks point to adherent junctions. (D) Graph showing the length of microvilli for the indicated genotypes (Figure S4A; STAR Methods). Mean \pm SEM analyzed by unpaired t test is shown; ${ }^{\star \star \star \star} p<$ 0.0001 .

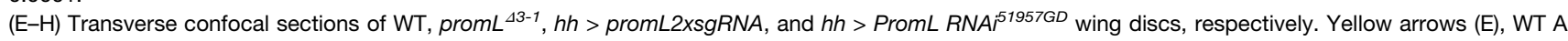
compartment $(G)$, and arrowheads $(F)$ are shown; PromL-depleted $P$ compartment in $(G)$ and $(H)$ mark the apical and subapical subcellular distribution of Hh, respectively.

(I and J) Confocal XY single sections showing Hh target gene expression in $h h>$ PromL RNAi ${ }^{51957 G D}$ (I) and in WT (J) discs. Red dots in the insets depict the number of cells expressing En, Ptc, and dpp-lacZ for the shown discs but representative of all examined discs $\left(\mathrm{WT}, \mathrm{n}=8\right.$; PromL RNA ${ }^{51957 G D}$, $\mathrm{n}=6$; Table 1$)$. (K-M) Quantification of En, Ptc, and dpp-lacZ intensity plotted as a function of distance from A/P boundary representative for all examined discs (WT, $\mathrm{n}=8$; Prom $L$ $\left.R N A i^{51957 G D}, \mathrm{n}=6\right)$. Note the decrease of $d p p-L a c Z$ intensity in PromL-depleted discs. Broken lines delimit V/D and A/P compartments.

Scale bars, $1 \mu \mathrm{m}(\mathrm{C}) ; 10 \mu \mathrm{m}(\mathrm{E}-\mathrm{H}) ; 20 \mu \mathrm{m}$ (B, I, and J). See also Figures S1-S4. 


\section{$\$$ CellPress}

\begin{tabular}{|c|c|c|c|}
\hline \multicolumn{4}{|c|}{ Mean number of cells expressing genes } \\
\hline Genotype & En & Ptc & dpp-lacZ \\
\hline WT $(n=12)$ & $2( \pm 0.42)$ & $3.7( \pm 0.4)$ & $7.6( \pm 0.5)$ \\
\hline$h h>$ PromL RNAi ${ }^{51957 G D}$ & $2^{\mathrm{a}}$ & $3.8( \pm 0.3)^{a}$ & $2.6( \pm 0.5)^{b}$ \\
\hline$h h>$ PromL RNAi $i^{102612 K K}$ & $2( \pm 0.4)^{a}$ & $3.7( \pm 0.4)^{a}$ & $3( \pm 0.3)^{b}$ \\
\hline$d i s p^{\text {SO37707 }}$ & n.d. & n.d. & $2.5( \pm 0.5)^{\mathrm{b}}$ \\
\hline$h h>A T P 8 B R N A i^{102648 K K}$ & $1.92( \pm 0.29)^{a}$ & $3.7( \pm 0.4)^{\mathrm{a}}$ & $4( \pm 0.3)^{b}$ \\
\hline$h h>$ Qua RNAiGD ${ }^{51957 G D}$ & $1.92( \pm 0.3)^{a}$ & $4^{a}$ & $3.8( \pm 0.3)^{b}$ \\
\hline$h h>$ Qua $R N A i^{100856 K K}$ & $1.91( \pm 0.3)^{\mathrm{a}}$ & $3.8( \pm 0.3)^{\mathrm{a}}$ & $4( \pm 0.3)^{b}$ \\
\hline$h h>$ Fim $R N A i^{47514 G D}$ & $1.9( \pm 0.3)^{\mathrm{a}}$ & $3.9( \pm 0.4)^{a}$ & $4( \pm 0.3)^{b}$ \\
\hline$h h>$ Fim $R N A i^{47511 G D}$ & $1.97( \pm 0.3)^{a}$ & $3.8( \pm 0.4)$ & $4.2( \pm 0.4)^{b}$ \\
\hline$h h>$ Fim $R N A i^{46028 G D}$ & $2.2( \pm 0.5)^{\mathrm{a}}$ & $3.9( \pm 0.3)^{\mathrm{a}}$ & $4.1( \pm 0.4)^{b}$ \\
\hline$h h>$ Fim $R N A i^{46029 G D}$ & $1.97( \pm 0.3)^{\mathrm{a}}$ & $3.7( \pm 0.4)^{a}$ & $4.1( \pm 0.4)^{b}$ \\
\hline promL $^{\Delta 3-1}$ & $2^{a}$ & $3.98( \pm 0.06)^{\mathrm{a}}$ & $3.6( \pm 0.6)^{b}$ \\
\hline$h h>$ UASPromL GFP & n.d. & $3.9( \pm 0.2)^{a}$ & $10.3( \pm 0.4)^{\mathrm{b}}$ \\
\hline \multicolumn{4}{|c|}{$\begin{array}{l}\text { The number of cells expressing En, Ptc, and dpp-lacZ was assessed in } \\
\text { the rectangles in Figures } 1 \mathrm{l}, 1 \mathrm{~J}, 2 \mathrm{~K}, 3 \mathrm{G}, 3 \mathrm{H}, 4 \mathrm{H}, \mathrm{S} 2 \mathrm{~F}, \mathrm{~S} 2 \mathrm{G} \text {, and } \mathrm{S} 3 \mathrm{~A}- \\
\mathrm{S} 3 \mathrm{D} \text { in at least } 8 \text { different discs for each genotype. Mean } \pm \mathrm{SEM} \text { analyzed } \\
\text { by unpaired } \mathrm{t} \text { test. n.d., not determined; n.s., not significant. } \\
{ }_{\mathrm{a}} \mathrm{p}<0.0001 \\
{ }^{\mathrm{b}} \text { n.s. }\end{array}$} \\
\hline
\end{tabular}

1B, S2B, and S2C). Quantitative analysis revealed that the RNAi against PromL protein reduced the PromL signal similarly to that measured in the promL mutant discs (50\%-60\%), validating the use of this genetic tool (Figure S1J). In contrast, WT discs or WT compartments displayed a dot-like pattern of PromL, presumably resulting from cross-sections of the apical protrusions, reflecting a correct organization of microvilli (Figures 1A, 1B, S1F, S1G, S1K, and S2D). We concluded that the absence or knockdown of PromL compromises the proper organization of the apical membrane.

A closer inspection of the ultrastructure of the wing imaginal disc epithelium by transmission electron microscopy (TEM) showed that $\mathrm{P}$ cells of $h h>$ PromL RNAi wing discs displayed abnormal microvilli or severely atrophic protrusions with a length $98 \%$ shorter than that of microvilli from WT discs (Figures 1C, 1D, S4A, S4C, and S4D). In contrast, in A WT cells, microvilli length, density, and morphology were similar to that of the WT discs (Figures 1C, 1D, and S4B). These findings point to the requirement of PromL for the maintenance and integrity of the proper microvilli architecture in the wing disc epithelium, consistent with the recent observation that the homologous prominin-1 modulates microvilli architecture in mammalian cells. ${ }^{28}$ Furthermore, our results establish that members of the Prominin protein family are key determinants of microvilli formation and integrity, putting forward the existence of a conserved function of the Prominin protein family through evolution.

PromL depletion impairs Hh distribution to microvilli and its long-range activity

Having established that PromL localizes to and is required for the maintenance and integrity of microvilli, we explored its relationship with the distribution of $\mathrm{Hh}$ as well as its impact on the

\section{Current Biology}

signaling properties of the morphogen. We first examined the subcellular distribution of $\mathrm{Hh}$ in WT, promL ${ }^{43-1}$ mutant, as well as in the $\mathrm{P}(h h>)$ PromL depleted compartment of wing imaginal discs by using both the conditional promL2xsgRNA mutant and the induced PromL RNAi. We found that, in WT discs and in A WT compartment, Hh distributed at the uppermost apical surface above E-cad (Figures 1E and 1G). Such distribution was not observed in promL ${ }^{\Delta 3-1}$ mutant discs (Figure 1F) or in PromLdepleted compartment (Figures 1G, 1H, S2B, and S2D), in which microvilli were absent or misshapen (Figures 1C and 1D), suggesting therefore that these structures support the apical distribution of Hh. Consistently, in PromL-depleted cells, Hh was detected at the level of Dlg and below E-cad (Figures 1F$1 \mathrm{H}$ and $\mathrm{S} 2 \mathrm{~B}$ ). A subsequent quantitative analysis of the signal distribution revealed a substantial reduction of $\mathrm{Hh}$ staining at microvilli in P cells (Figures S2D and S2E; STAR Methods), further supporting that the apical distribution of $\mathrm{Hh}$ relies on the presence of intact microvilli.

To examine the consequences of the subcellular redistribution of $\mathrm{Hh}$ in PromL-depleted cells on Hh signaling properties, we monitored the expression of long- and short-range $\mathrm{Hh}$ target genes simultaneously in promL ${ }^{43-1}$ and $h h>$ PromL $R N A i$ wing imaginal discs. The $d p p-l a c Z$ reporter expression reflects the apical secretion and the long-range Hh signaling, whereas En and Ptc expression is attributed to Hh short-range activity mediated by its basolateral secretion. ${ }^{6,7}$ We found that, in both promL ${ }^{\Delta 3-1}$ and in PromL knockdown discs, the shortrange target genes, En and Ptc, remained unaltered (Figures 1I-1L, S2F, S2G, S2I, and S2J; Table 1). In contrast, Hh longrange signaling was impaired, as evidenced by a severe decrease of $d p p$ expression ranging from $60 \%$ to $65 \%$ (Figures $1 \mathrm{I}, 1 \mathrm{M}, \mathrm{S} 2 \mathrm{~F}-\mathrm{S} 2 \mathrm{H}$, and S2K; Table 1). This is associated with a $60 \%-65 \%$ reduction of the wing pouch size (Figure S2L), further confirming that decreasing apical $\mathrm{Hh}$ secretion is sufficient to affect the growth of the wing disc. This growth defect is partially compensated later during development: the adult wing size is decreased by only $15 \%$, and it is unrelated to vein pattern defects (Figures S3F and S3G). These results consistently establish that PromL, and hence intact microvilli, are not only required for the apical distribution of $\mathrm{Hh}$ but also critically involved in $\mathrm{Hh}$ long-range signaling in the wing disc epithelium.

\section{Dispatched mutants exhibit both altered microvilli and} impaired Hh long-range signaling

To substantiate the requirement of microvilli integrity for $\mathrm{Hh}$ long-range signaling, we chose to analyze the effect of Dispatched (Disp) protein on the microvillar localization of $\mathrm{Hh}$ as well as on microvilli integrity. Disp is a sterol-sensing domain (SSD)-containing protein involved in cholesterol homeostasis ${ }^{29}$ and a positive regulator of $\mathrm{Hh}$ secretion and trafficking. ${ }^{5,7,30} \mathrm{We}$ reasoned that, in disp mutant discs in which $\mathrm{Hh}$ is retained in producing cells and $d p p$ expression is severely restricted (Figure 2A; Table 1; compare to Figure $1 \mathrm{~J}$ ), the distribution of $\mathrm{Hh}$ to microvilli might also be impaired. The analysis of $\mathrm{Hh}$ distribution confirmed that, in disp mutant discs, Hh evenly distributed along the apico-basal axis at the level of $\mathrm{E}$-cad, ${ }^{7}$ but not to microvilli (Figures 2B and 2C), at odds with WT discs, in which $\mathrm{Hh}$ distributed to microvilli and colocalized with PromL $(50 \%$ of 


\section{Current Biology}

Article

A disp 5037707
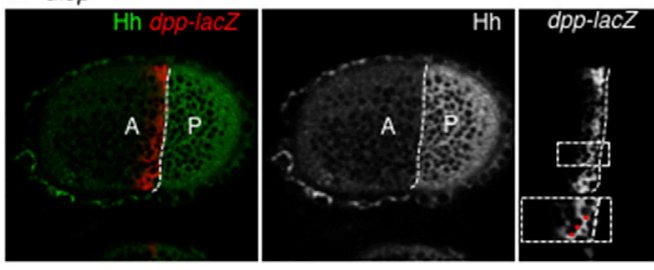

C

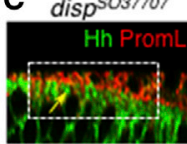

D $w t$
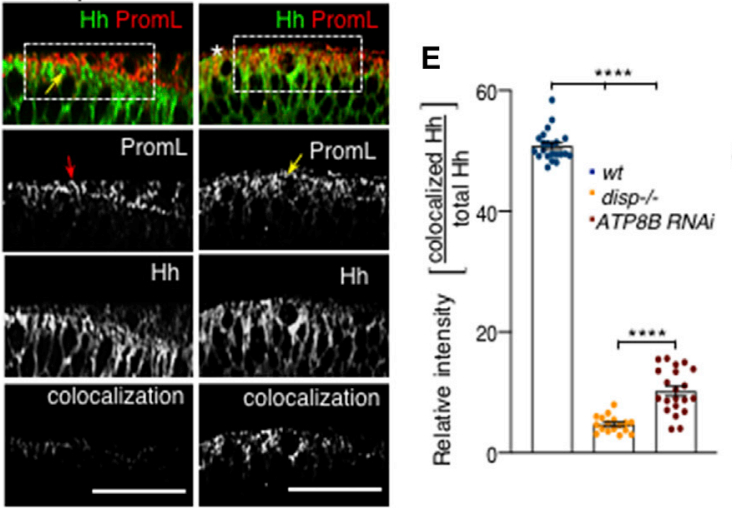

$\mathbf{H}_{h h>A T P 8 B} R N A i$
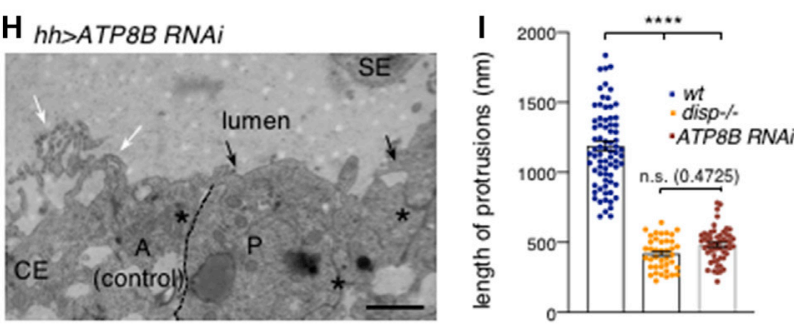

\section{K}

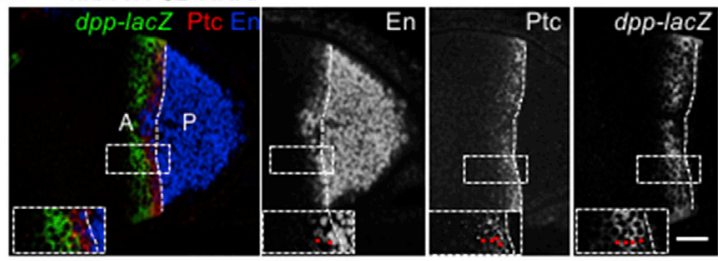

B disp 5037707

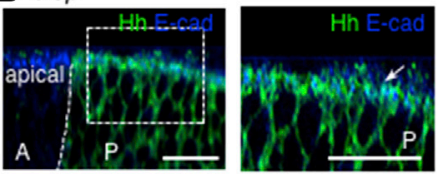

F disp ${ }^{5037707}$

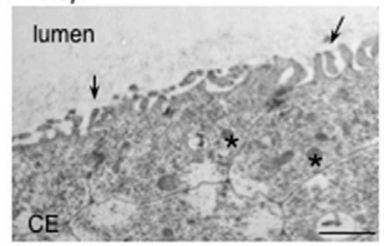

G $w t$

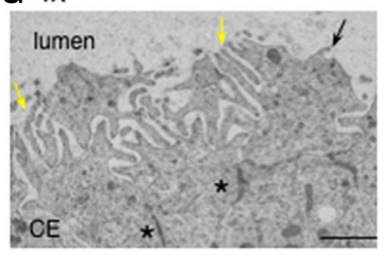

J $h$ h $>A T P 8 B R N A i$

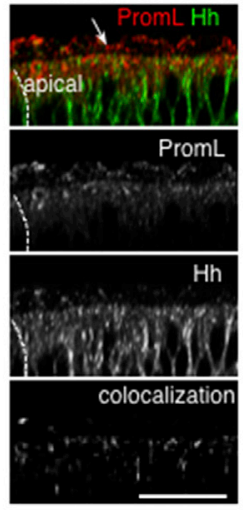

$\mathbf{L}$

dpp-lac Z

100 -ATP8B RNAi 102648KK

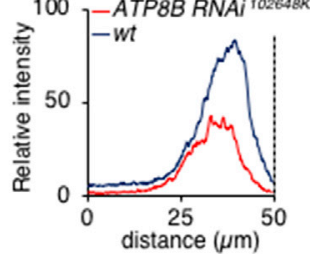

Figure 2. The absence of Disp and dATP8B activity perturbs microvilli integrity and impairs Hh long-range signaling

(A-D, I, and J) Single confocal sections of discs of the indicated genotypes stained for Hh (green; white), $\beta$-gal (red; green; white), E-cad (blue), PromL (red; white), En (blue; white), and Ptc (red; white).

(A) $\mathrm{Hh}$ is retained in $\mathrm{P}$ compartment, and dpp-lacZ expression is reduced to 4 cells (red dots in the inset; Table 1; compare to WT discs in Figure 1J). (B and $\mathrm{C}$ ) In disp mutant discs, Hh distributes along the apico-basal axis at the level of E-cad (white arrow) and below PromL (yellow arrow).

(C) Red arrow points to PromL staining, reflecting changes in microvillus length. The sharpness has been increased for a better visualization of the overall PromL staining.

(D) In WT discs, Hh colocalizes with PromL (asterisk, lowest panel and STAR Methods). PromL signal is typical of an intact organization of microvilli (yellow arrow).

(E) Quantification of the intensity colocalized $\mathrm{Hh}$ and total Hh (STAR Methods). Mean \pm SEM analyzed by unpaired $t$ test $\left({ }^{\star \star \star *} p<0.0001\right)$ is shown; n.s., not significant $(n=18 ; 6$ discs/genotype).

(F-H) TEM of disp mutant, WT, and $h h>A T P 8 B R-$ $N A i$ wing discs. In disp mutant $(\mathrm{F})$ and in the $\mathrm{P}$ compartment of $h h>A T P 8 B R N A i$ disc $(\mathrm{H})$, microvilli are shorter (black arrows) than in control disc (G) and $A$ compartment in $(\mathrm{H})$ (yellow arrows). Asterisks depict adherent junctions.

(I) Graph reporting microvilli length. Mean \pm SEM analyzed by unpaired $t$ test $\left({ }^{\star \star \star \star} p<0.0001\right)$ is shown.

(J) In ATP8B depleted disc, Hh distributed subapically (arrow) and $\mathrm{Hh} / \mathrm{PromL}$ colocalization is reduced as compared to WT (D).

(K) Confocal sections showing $\mathrm{Hh}$ target gene expression in hh>ATP8BRNAi disc. Red dots in the insets indicate the cells expressing En, Ptc, and $d p p$-lacZ for the shown discs but representative of all examined discs $(n=5$; Table 1$)$.

(L) Quantification of $d p p$-lacZ intensity plotted as a function of distance from A/P boundary representative for all examined discs.

Scale bar, $20 \mu \mathrm{m}$ (A-D, J, and K); $1 \mu \mathrm{m}(\mathrm{F}-\mathrm{H})$. White dashed line delimits A/P compartments. See also Figures S1-S4.

the uppermost apical Hh signal; Figures 2D and 2E). Accordingly, long-range $\mathrm{Hh}$ signaling is impaired in disp mutants (Figure $2 \mathrm{~A}$ ). We also noticed that PromL signal was more punctate and irregularly spiky in disp mutant wing discs (Figure 2C), as compared to WT discs (Figures 2D and S1K). In agreement with previous reports, ${ }^{15,31}$ these observations point to a redistribution of PromL over non-protruding areas of the plasma membrane that could be likely correlated to a shortening of microvilli.

Additional ultrastructural analysis of disp mutant discs indeed showed that microvilli were shorter and less numerous in this genetic background ( $66 \%$ of that of the WT; Figure $2 \mathrm{G}$ ), with an average of $2.9 \pm 1.16$ microvilli per cell (Figures $2 \mathrm{~F}, 2 \mathrm{G}, 2 \mathrm{I}$, and S4B). Together, these experiments reinforce the idea that a proper organization of apical membrane and the maintenance of microvilli architecture is critical for Hh-long-range signaling. They also suggest that, in addition to its role on $\mathrm{Hh}$ secretion and trafficking, 5,7,30 Disp modulates microvilli architecture, possibly by controlling the distribution of cholesterol in the plasma membrane leaflets, ${ }^{12}$ facilitating thereby the selective localization of PromL to microvilli through cholesterol binding. Consistent with this hypothesis, extraction of plasma membrane cholesterol results in the loss of the specific distribution of prominin-1 to microvilli. ${ }^{15}$ 


\section{$\infty$ CellPress}

Integrity of plasma membrane phospholipids and of actin cytoskeleton is required for maintaining microvilli integrity and Hh long-range signaling

The maintenance of the structure of the apical plasma membrane relies on the asymmetrical distribution of specific phospholipids between the outer and inner leaflets of the plasma membrane. ${ }^{32}$ This is controlled by members of the P4-type ATPases, known as phospholipid flippases, which include four members (ATP8B1-4) in human and only one in Drosophila (dATP8B). ${ }^{33}$ In mammals, depletion of ATP8B1 perturbs the organization of the apical membrane, stereocilia, and microvilli integrity. ${ }^{34,35}$ It is thus expected that abrogation of dATP8B activity could perturb microvilli organization and hinder $\mathrm{Hh}$ long-range signaling also in the wing imaginal disc. Indeed, the qualitative and quantitative TEM analysis revealed that dATP8B depletion in $\mathrm{P}$ cells $(h h>$ ATPB8 RNAi) resulted in an alteration of microvilli number, length, and morphology (Figures $2 \mathrm{H}, 2 \mathrm{I}$, and S4B and compare to A control compartment in Figure $2 \mathrm{H}$ ) and perturbed the characteristic dot-like staining pattern of PromL, indicative of the proper microvilli integrity (Figure 2J and compare to Figures 2D and S1K). This was accompanied by a subapical redistribution of $\mathrm{Hh}$, an impairment of PromL-Hh colocalization (Figures $2 \mathrm{E}$ and $2 \mathrm{~J}$ ), the reduction of $d p p$ expression in recipient cells (Figures $2 \mathrm{~K}$ and 2L; Table 1; compare to Figure 1J) and by the decrease of the wing pouch size (Figure S2L) as a consequence of the compromised Hh long-range signaling. In contrast, no effect on the short-range $\mathrm{Hh}$ target genes (i.e., En and Ptc) was observed (Figure 2K; Table 1; compare to Figure 1J). However, dATP8B-depleted cells exhibit well-developed adherent junctions, indicating that they are still able to establish a correct polarity (Figure $2 \mathrm{H}$ ). These results show that a deficiency of dATP8B activity in the wing disc epithelium interferes with the distribution of PromL to microvilli and, as a consequence, perturbs Hh long-range signaling. They also suggest the involvement of phospholipids in this process. In line with this, ATP8B1, which specifically localizes in the stereocilia, maintains the phospholipid asymmetry of the cellular membranes by possibly translocating phosphatidylserine from the outer to the inner leaflet of the membrane. ${ }^{34}$ However, the nature of the phospholipids that dATP8B is predicted to translocate in the wing disc epithelium remains to be established.

The cellular protrusions, including microvilli, that occur at the apical plasma membrane of epithelial cells are known to depend on the formation of actin bundles regulated by actin-binding proteins, such as villin and Fimbrin (Fim). ${ }^{36,37}$ To test this possibility, we silenced two actin-binding proteins, quail (Qua), the Drosophila villin-like protein, and Fim in the $\mathrm{D}(\mathrm{ap}>)$ ) or the $\mathrm{P}(h h>)$ compartments of the Drosophila imaginal discs. In both conditions, PromL levels were drastically reduced in the depleted $\mathrm{D}$ compartment (Figures 3A3C; compare to WT V compartment), and microvilli, when present, were strongly defective (Figures 3D-3F and S4B). Accordingly, Hh long-range signaling was impaired to similar extents in both genetic backgrounds, as confirmed by the subapical distribution of $\mathrm{Hh}$ and PromL (Figures $3 \mathrm{~A}$ and $3 \mathrm{~B}$ ), by the reduction of $d p p$ expression (Figures $3 G-3 I$ and S3A-S3E; Table 1; compare to Figure 1J), and of the wing pouch size (Figure S2L).

\section{Current Biology}

This indicates that the disassembly of actin filaments caused profound structural alterations on the microvillar architecture and put forward the positive contribution of actin cross-linking factors in this process. Moreover, this reveals that an interplay between PromL and cytoskeleton components contributes to the biogenesis and maintenance of microvilli and is critical for Hh long-range signaling.

Microvilli are the site of EV biogenesis and release While previous work has established that microvilli give rise to prominin-containing $\mathrm{EVs},{ }^{19}$ their contribution to intercellular communication during development was never directly demonstrated. Considering the requirement of microvilli for Hh longrange signaling (as shown above), we reasoned that EVs could bud from microvilli and serve as a means to transport $\mathrm{Hh}$ to distant recipient cells. To test this assumption, we performed an EM analysis of serial sectioning of the WT wing imaginal discs epithelium (Figures $4 \mathrm{~A}, 4 \mathrm{C}$, and S4C). We noticed the presence of small vesicular structures of $60-150 \mathrm{~nm}$ diameter free within the lumen and distant from microvilli. The content of these small vesicular structures is less electron dense than the cytoplasm of microvilli, indicating that they do not represent horizontal sections of adjacent microvilli (Figures 4A, 4C, and S4C; STAR Methods).

Importantly, such vesicular structures were not detected in discs depleted for PromL, dATP8B, Qua, Fim, or disp mutant discs, in which microvilli are absent or atrophic (Figures $1 \mathrm{C}$, $2 \mathrm{~F}, 2 \mathrm{H}, 3 \mathrm{D}, 3 \mathrm{E}, \mathrm{S} 4 \mathrm{~B}$, and S4E). In addition, dpp expression and the wing pouch size were substantially decreased (Figures $1 \mathrm{I}, 1 \mathrm{M}, 2 \mathrm{~A}, 2 \mathrm{~K}, 2 \mathrm{~L}, 3 \mathrm{G}-3 \mathrm{I}, \mathrm{S} 2 \mathrm{~F}-\mathrm{S} 2 \mathrm{H}, \mathrm{S} 2 \mathrm{~K}, \mathrm{~S} 2 \mathrm{~L}$, and S3A-S3E; Table 1; compare to Figure 1J), underscoring the correlation between the presence of microvilli, the occurrence of these secreted vesicles, and Hh long-range activity (STAR Methods). We also observed that MVB with intraluminal vesicles (ILVs) of smaller diameter (25-40 nm) were consistently found at close vicinity of the basolateral plasma membranes (Figures 4A, 4B, and S4D), but not at the apical site, indicating that MVBs probably do not contribute to an apical secretion of "endosome-derived" exosomes. ${ }^{4}$

A closer inspection of the microvilli in WT discs revealed the presence of buds at the microvillar membrane (Figures $4 \mathrm{C}$ and S4C). Electron tomography and 3D reconstructions of the apical plasma membrane confirmed the existence of buds still connected to the microvillar membrane but also of isolated free vesicles within the extracellular space certainly after fission (Figure 4D; Videos S1 and S2). Together, these results substantiate microvilli as a site of EV biogenesis and demonstrate that the active interplay between PromL, actin cross-linking proteins, and microvilli lipids is critical for the maintenance of microvilli integrity and the biogenesis of EVs. Consistent with these findings, prominin-1-containing EVs were shown to originate from microvilli and cilia of neuroepithelial and neural progenitor cells, respectively. ${ }^{19,38}$ In addition, actin mediates EV release from the tip of cilia ${ }^{39}$ and dATP8B protein is concentrated in the cilia of olfactory neuron dendrites, ${ }^{40}$ where it could play similar roles as the one shown here in microvilli.

\section{EVs mediate Hh long-range signaling}

Given that PromL is critical for microvilli biogenesis and that $\mathrm{Hh}$ distributed to microvilli where it colocalizes with PromL (Figures 


\section{Current Biology} Article

A
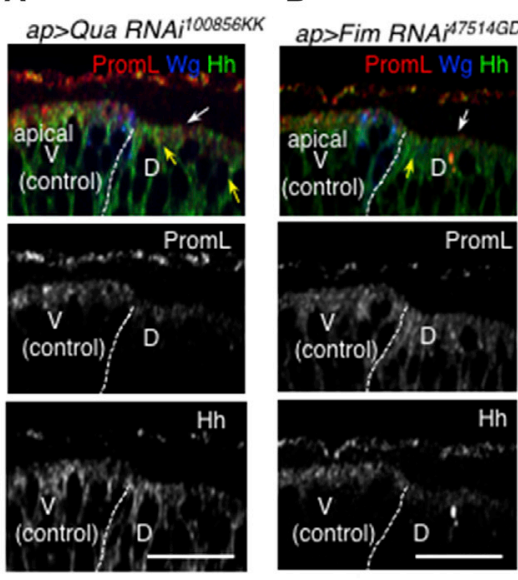

D
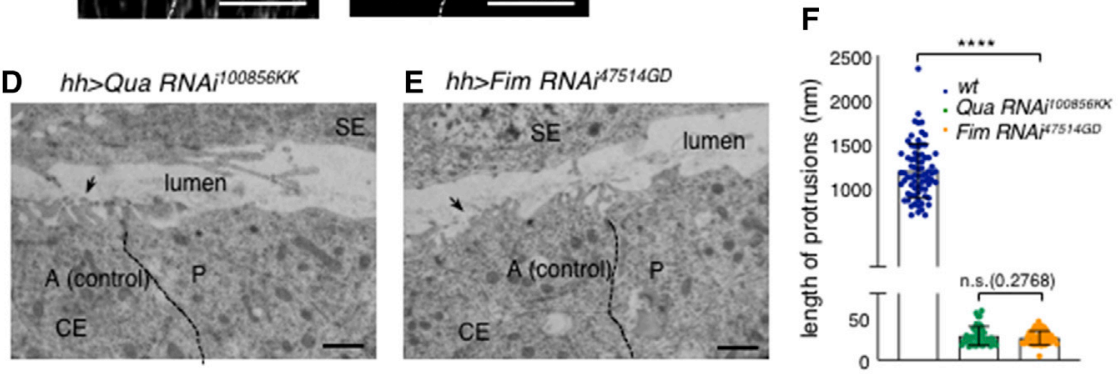

G $h$ h $>$ Qua RNAitooss6KK
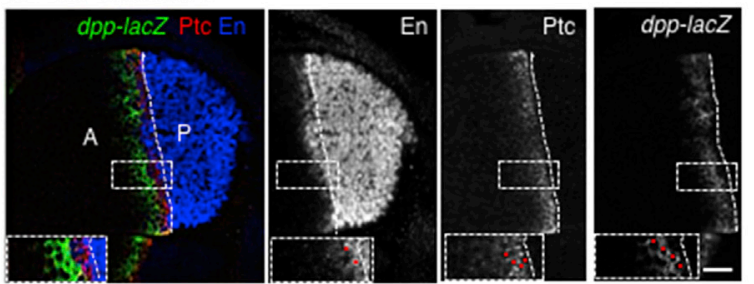

H hh>Fim RNAi 4754460
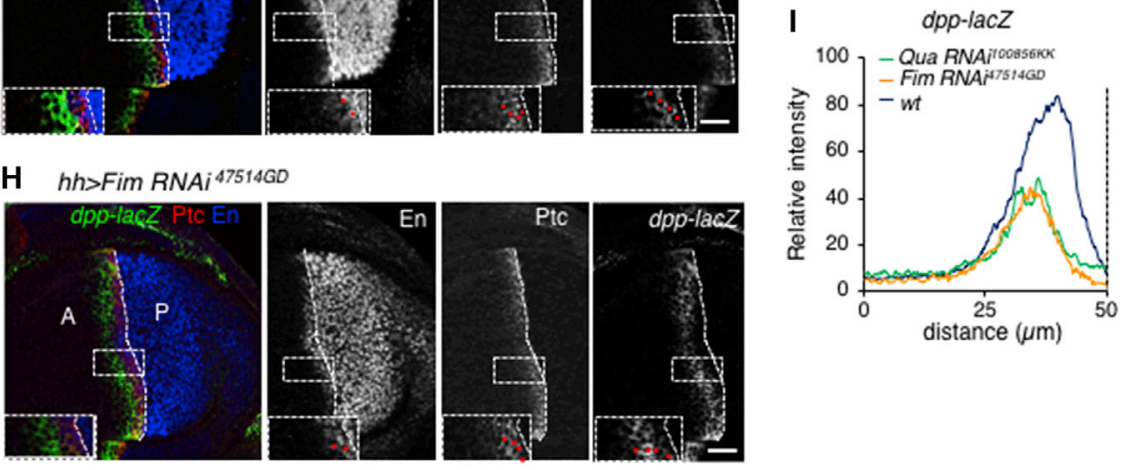

S2D, S2E, 2C-2E, 2I, and 3A-3C), we reasoned that an increase of $\mathrm{EV}$ biogenesis might be correlated with an increase of $\mathrm{Hh}$ longrange activity. To test this assumption, we examined the consequences of the overexpression of PromL-GFP in Hh-producing cells ( $h$ h > PromL-GFP). TEM analysis revealed a substantial increase in EV number in PromL-GFP discs (35\% as compared to WT), which is accompanied by a slight, but not significant, reduction in microvilli number and length (Figures $4 \mathrm{E}, 4 \mathrm{~F}, \mathrm{~S} 4 \mathrm{~B}$, and S4E). We also found that overexpression of PromL-GFP promoted a massive $\mathrm{Hh}$ release into the lumen, correlated with a significant expansion of the dpp expression domain (Figures 4G-4l; Table 1; compare to Figure 1J). The correlation coefficient between Hh-PromL colocalization and the number of microvilli per cell (0.8789) on the one hand and, on the other hand,

\section{$\infty$ CellPress}

Figure 3. Actin cytoskeleton components contribute to microvilli architecture and $\mathrm{Hh}$ long-range signaling

(A, B, G, and H) Single confocal sections of discs of the indicated genotypes stained for PromL (red; white), aPKC (green), E-cad (blue), Hh (green; white), Wg (blue), En (blue; white), Ptc (red; white), and $\beta$-gal (red; white).

(A and B) Distribution of $\mathrm{Hh}$ and PromL for the indicated genotypes. In D compartment, where PromL was depleted, white and yellow arrows depict the absence of PromL staining at microvilli and the basolateral distribution of $\mathrm{Hh}$, respectively, as compared to WT V control compartment. Note also the absence of colocalization of $\mathrm{Hh}$ and PromL in D compartment.

(C) Quantification of the intensity of colocalized $\mathrm{Hh}$ and total Hh (STAR Methods). Mean \pm SEM analyzed by unpaired $t$ test $\left(^{\star \star \star \star} p<0.0001\right)$ is shown. Between 8 and 15 discs were analyzed.

( $D$ and $E$ ) TEM of transverse sections of wing imaginal discs of the indicated genotype showing microvilli in the A compartment (black arrows) and adherent junctions (asterisk). Note that, in the $\mathrm{P}$ compartment, microvilli are reduced in size or absent.

(F) Histogram of microvilli length. Mean \pm SEM analyzed by unpaired $t$ test $\left(^{\star \star \star *} p<0.0001\right)$ is shown.

( $G$ and $H) X Y$ confocal sections of wing imaginal discs from the indicated genotypes stained for En (blue; white), Ptc (red; white), and $\beta$-gal (green; white) showing $\mathrm{Hh}$ target gene expression. Red dots in the insets indicate the cells expressing En, Ptc, and dpp-lacZ for the shown discs but representative of all examined discs (Quail RNA ${ }^{10856 K K}$ $\mathrm{n}=7 ;$ Fim RNAi ${ }^{47514 G D} \mathrm{n}=6$; see Table 1 and compare to WT disc in Figure $1 \mathrm{~J}$ ).

(I) Quantification of $d p p$-lacZ intensity plotted as a function of distance from A/P boundary representative for all examined discs.

White $(A, B, G$, and $H)$ and black broken lines $(D$ and $E$ ) delimit the $V / D$ or $A / P$ compartments, respectively. Scale bar, $1 \mu \mathrm{m}$ ( $D$ and $E) ; 20 \mu \mathrm{m}$ (A, $B$, G, and H). See also Figures S2-S4.

the correlation coefficient between $\mathrm{Hh}$ PromL colocalization and the number of cells expressing $d p p$ (0.9624) uncover the significant relationship between these events and further support our findings (STAR Methods). Altogether, these results emphasize the interdependence between microvillar distribution of PromL, EV biogenesis, and Hh long-range activity that might fine-tune Hh long-range signaling.

In light of these results, we anticipated that microvilli-derived EVs, containing both $\mathrm{Hh}$ and PromL protein, could be released into the extracellular medium. To formally validate this hypothesis, we investigated their occurrence and their potential properties in wing discs overexpressing PromL-GFP and Hh tagged with red fluorescent protein (Hh-RFP) in Hh-producing cells ( $h h$ $>$ Hh RFP; PromL GFP). In a first round of experiments, we examined the distribution of Hh-RFP and Prom-GFP using immunoelectron microscopy (IEM) for a qualitative analysis. In agreement 
A

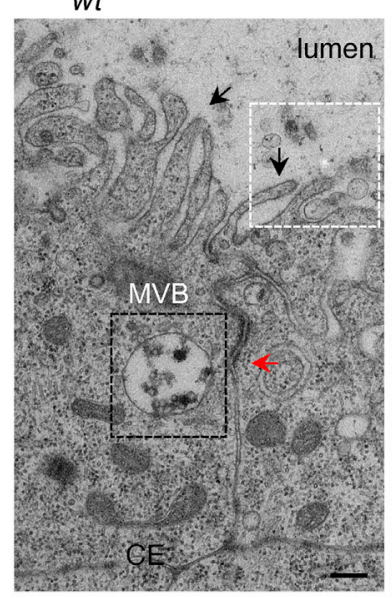

C

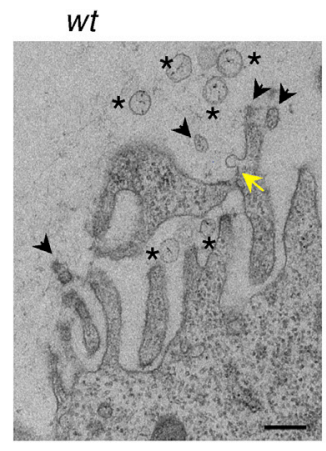

$\mathbf{E}$

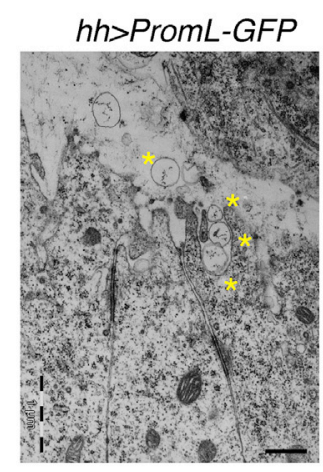

G

ap>PromL-GFP

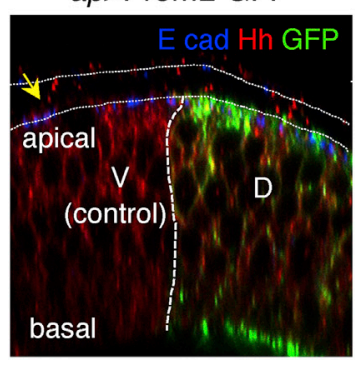

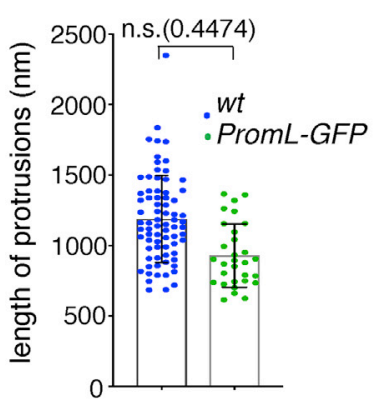

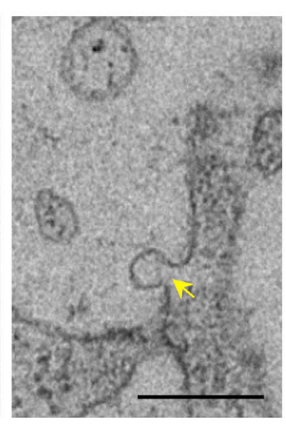

D

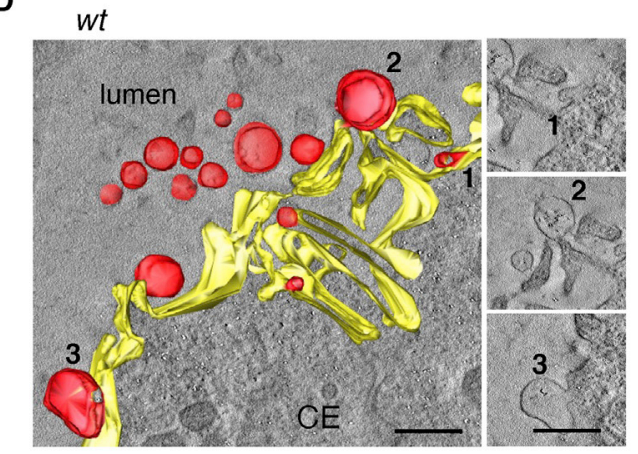

H

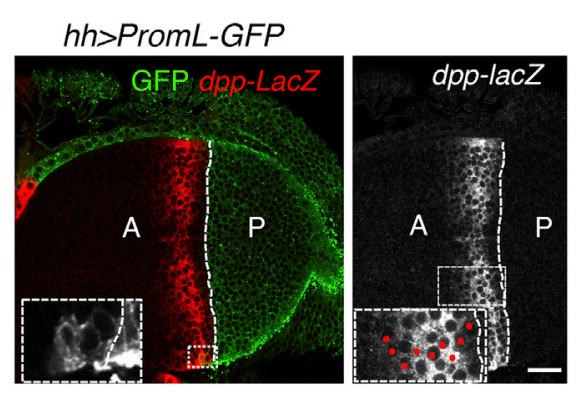

I

dpp-LacZ
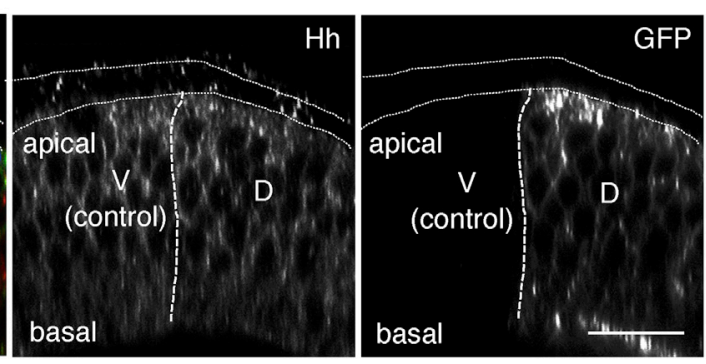


\section{Current Biology Article}

with all our above observations (Figures S2D, S2E, 2C-2E, 2I, and $3 A-3 C$ ), both proteins localized not only to microvilli but also to the surface of EVs (Figures 5A and 5B). To follow their dynamics, we monitored by confocal live imaging the movement of EVs released by the $\mathrm{P}$ compartment within the extracellular space. These experiments, performed in $h h>$ Hh RFP; PromL GFP discs, revealed that particles enclosed in a membranous structure emanate from the $\mathrm{P}$ compartment where they are produced, move toward the A compartment, and are detected between the squamous and the columnar epithelium (Figures 5C-5G and S5A-S5F; Video S3). The majority of EVs released by the $\mathrm{P}$ compartment were positive for Hh-RFP and PromGFP (80\%), whereas the others only displayed Hh-RFP (Figure $5 \mathrm{E})$. These EVs were not static but engaged in a dynamic movement from the $\mathrm{P}$ toward the $\mathrm{A}$ compartment and trafficked associated to one another within the extracellular space (Figures 5C-5G and S5A-S5F; Video S3). The EVs are very likely the extracellular carriers of $\mathrm{Hh}$, facilitating thereby its long-range activity. These results are consistent with our hypothesis that microvilli of the wing disc epithelium are the site of generation of small EVs, which are critically involved in the transport of $\mathrm{Hh}$ across the tissue to facilitate its long-range activity.

\section{DISCUSSION}

Understanding the origin and function of EVs in vivo during development has so far been limited. Previous studies, based on ultrastructural, biochemical, and pharmacological observations, revealed only part of the mechanisms of EV biogenesis and did not directly investigate their functions in developmental processes in vivo. ${ }^{19,20}$ Here, the combination of electron and fluorescence microscopy, live imaging, cell biology, and genetic approaches allowed us to unveil that microvilli-derived EVs provide means for exchanging signaling cues between cells at a distance.

We found that PromL, by interacting with lipids and cytoskeleton components, is a key determinant of microvilli formation in vivo, whose integrity is critical for the biogenesis of $\mathrm{EVs}$ and their signaling role. We uncovered that microvilli are the preferential site for the generation of small EVs-different from exosomes - that ferry $\mathrm{Hh}$ from producing to recipient cells. Finally, we demonstrated that microvilli-derived EVs contribute to $\mathrm{Hh}$ long-range, but not to short-range, activity in the wing disc epithelium. These findings provide firm evidence for a previously unidentified mechanism of $\mathrm{Hh}$ release and transport mediating Hh long-range activity.

Previous reports suggested that a mixed population of EVs (exosomes and ectosomes) is released at the basolateral site of epithelial cells, travels along cytonemes, and contributes thereby to the graded $\mathrm{Hh}$ distribution that mediates its shortand long-range activity. ${ }^{9,10,13}$ Such $\mathrm{Hh}$ distribution and release requires, first, the recycling of $\mathrm{Hh}$ from apical to basal compartments and, second, the loading of Hh-coated EVs on cytonemes. ${ }^{9,13}$

In the presented work, we did not examine the presence of cytonemes that are only detectable upon forced expression of the Hh co-receptor interference hedgehog (Ihog). ${ }^{9,12,13}$ Instead, we demonstrate that small EVs bearing $\mathrm{Hh}$ and PromL (ectosomes or microvesicles) are released from the apical pole of $\mathrm{Hh}$-producing cells and are detected within the lumen between squamous and columnar cells of the wing discs in the $A$ compartment (Figures 4A, 4C, 4D, and S4C). This also validates our previous observations establishing that $\mathrm{Hh}$ is recycled back to the apical membrane of producing cells before it is secreted at the apical to deploy its long-range activity. ${ }^{6-8}$ Here, we observed that small EVs bud from microvilli, but not from ILVs (Figures 4A-4D). Thus, impeding the apical distribution of $\mathrm{Hh}$ and EVs biogenesis at microvilli solely interferes with $\mathrm{Hh}$ long-range activity, but not with its short-range activity.

Because (1) microvilli and cytonemes are two different structures; (2) in epithelial cells, prominin distributes to microvilli and cilia at the apical surface, but not to the basolateral compartment (this study and Dubreuil et al. ${ }^{38}$ and Corbeil et al. ${ }^{41}$ ); and (3) no data have reported a requirement of PromL for cytoneme formation, we reasoned that it is very unlikely that microvilli-derived EVs could be loaded on cytonemes.

We thus propose that exosomes produced at the basolateral site only convey $\mathrm{Hh}$ short-range activity and that the small EVs produced from microvilli at the apical pole of the epithelial cells mediate the long-range effect of the morphogen. This highlights an important role of epithelial cell polarity in segregating different categories of cell signaling systems.

Finally, microvilli-derived EVs are not involved in a general transport of lipid-modified morphogens because, in promL

Figure 4. EVs mediate Hh long-range signaling across the disc epithelium

(A, C, and E) TEM images of a transverse section of a WT wing imaginal discs.

(A) Microvilli (black arrows) and adherent junction (red arrowhead). Top right: magnification of the white boxed region shows vesicular structures in the lumen at the vicinity of the microvilli (asterisks). Bottom right: magnification of the black boxed region shows an MVB. Yellow arrows point to ILVs.

(B) Distribution of ILVs and EVs based on their diameter size (ILVs, $n=38 ; E V s, n=32$ ). Note that the diameter of ILVs is smaller than the one of EVs.

(C) EVs (asterisks) into the lumen close to microvilli where a bud is also visible (yellow arrows). Note that EVs are less electron dense than sections of microvilli (black arrowheads), indicating a different origin.

(D) 3D reconstruction and modelization of vesicles budding at microvilli. The buds (red) are still connected to the microvillar membrane (yellow), and free vesicles (red) are detected into the lumen. Right: vesicles 1-3 budding at microvilli correspond to the vesicles in (D).

(E) TEM of $h$ h>PromL-GFP disc showing EVs (yellow asterisks) into the lumen and close to microvilli (yellow asterisks).

(F) Histogram reporting the length of microvilli. Mean \pm SEM analyzed by unpaired $t$ test is shown.

( $G$ and $H$ ) ap>PromL-GFP (G) or $h h>$ PromL-GFP (H) discs stained for E-cad (blue), Hh (red; white), GFP (green; white), and $\beta$-gal (red; white).

(G) Hh (yellow arrow) is detected within the lumen (delimited by a white dotted line) in both $D$ and $V$ compartments.

(H) XY confocal section. Left: PromL-GFP is detected in A cells (yellow arrow). Right: cells expressing dpp-lacZ (red dots) in the inset are shown. Six to eight discs from each genotype were analyzed (see Table 1 and compare to Figure $1 \mathrm{~J}$ ).

(I) Quantification of $d p p-l a c Z$ intensity plotted as a function of distance from A/P boundary representative for all examined discs.

Broken lines delimit the V/D (G) or A/P (H) compartments. Scale bar, $0.2 \mu \mathrm{m}$ (A and C-E); $20 \mu \mathrm{m}$ (G and H). See also Figures S2-S4 and Videos S1 and S2. 
A

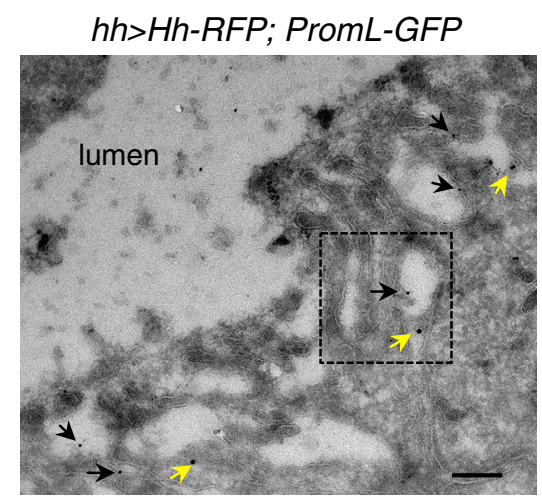

Hh-PAG $10 \mathrm{~nm}$

GFP-PAG $15 \mathrm{~nm}$

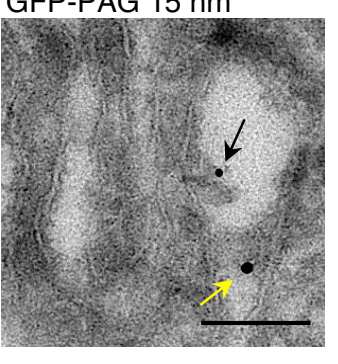

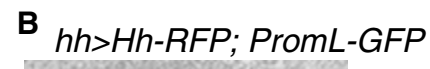

C

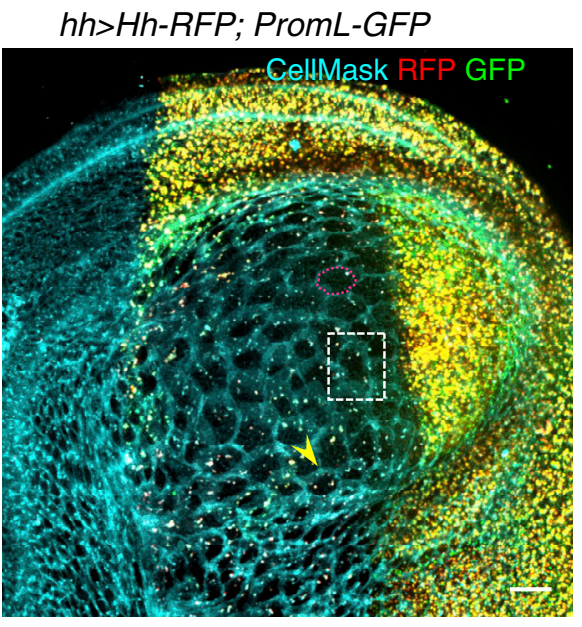

D

Dh>Hh-RFP; PromL-GFP
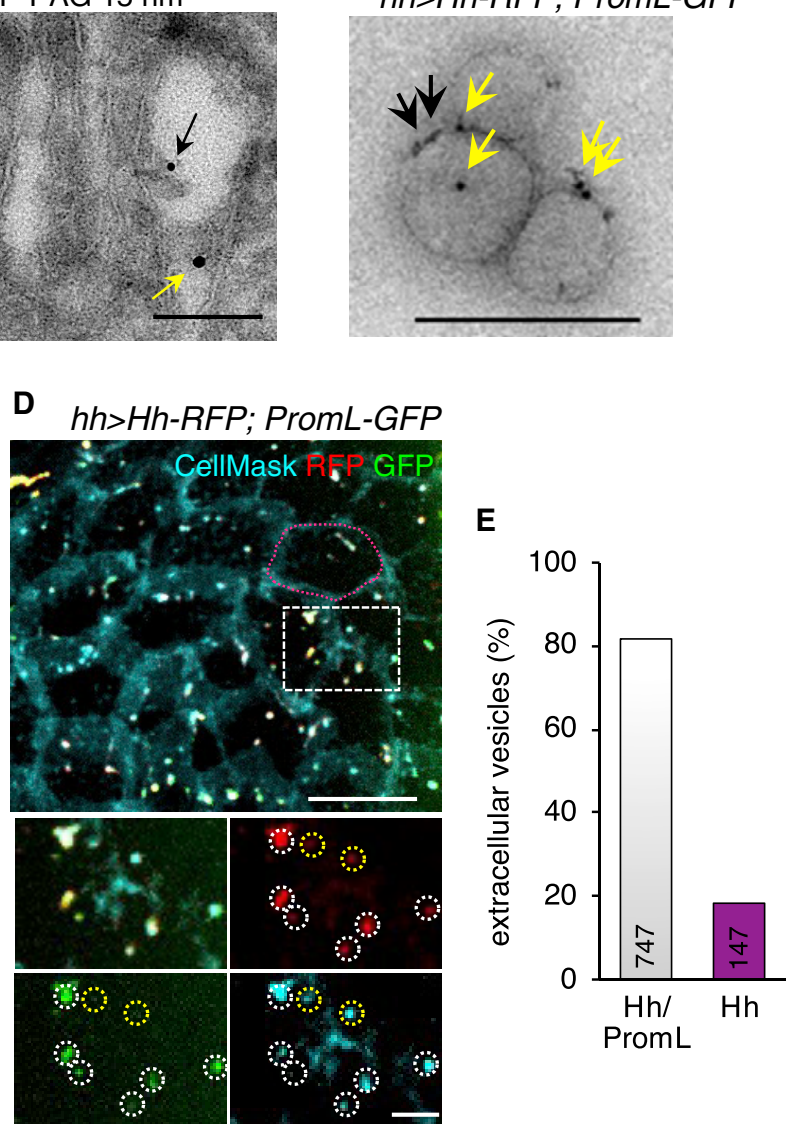

\section{F $h$ h $>$ Hh-RFP; PromL-GFP}
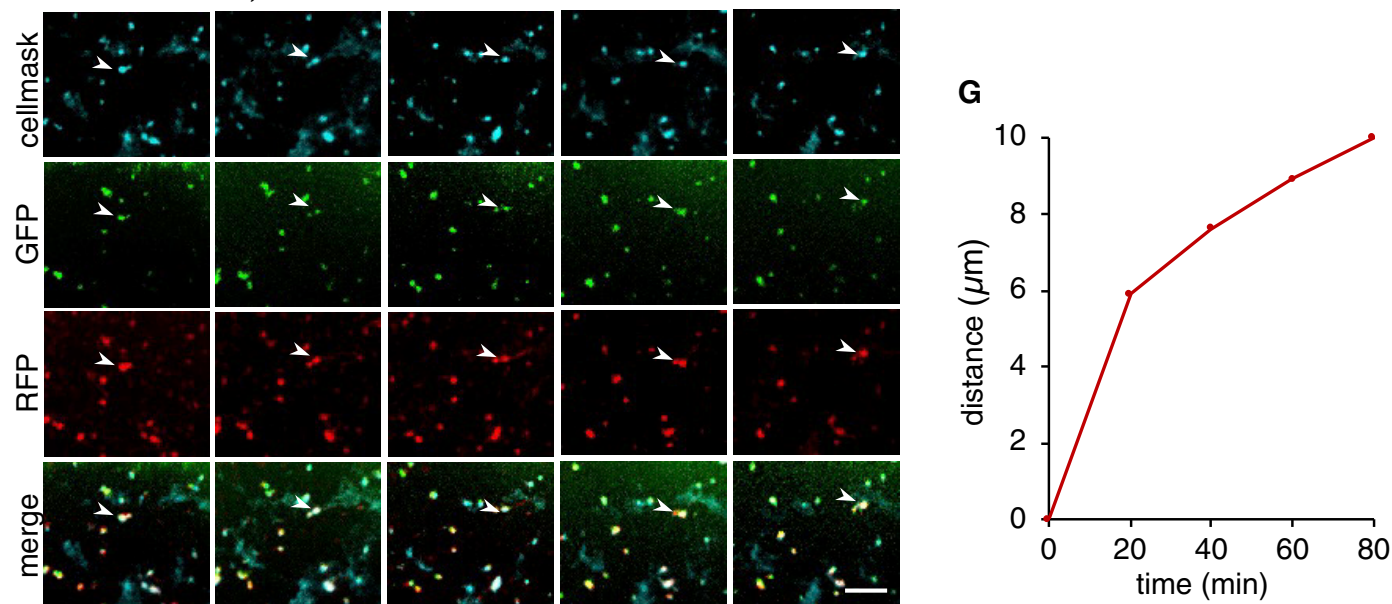

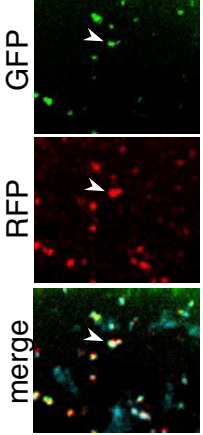

0

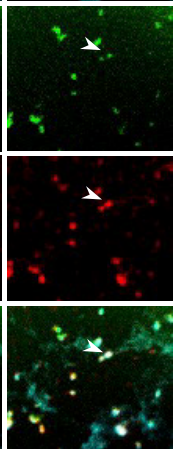

20

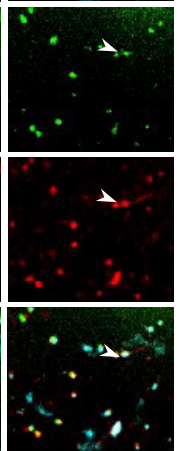

40

time $(\min )$

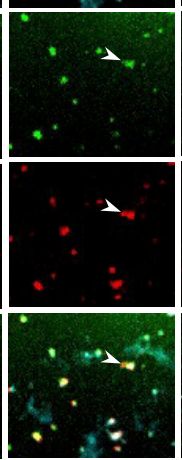

60

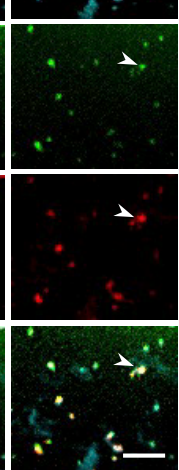

80

Figure 5. Hh/PromL-EVs move into the extracellular field

(A) Ultrathin cryosection of $h h$ > Hh RFP; PromL-GFP disc immunolabeled for Hh (PAG 10, black arrows) and GFP (PAG 15, yellow arrows) showing both proteins at microvilli.

(B) EVs detected into the lumen are positive for Hh (black arrow) and PromL (yellow arrow).

(C) Maximum intensity $z$ projection of 167 slices spaced $1 \mu \mathrm{m}$ apart of $h h>H h$-RFP; PromL-GFP disc recorded every 3 min. Plasma membrane was stained with CellMask (cyan). 


\section{Current Biology} Article

mutant wing discs, neither the distribution of Wingless $(\mathrm{Wg})$ (another lipid-modified morphogen that patterns the D/V axis in the wing imaginal disc) nor the expression of its short- and long-range target genes (Cut and DII, respectively) was affected (Figure S6).

Considering that $\mathrm{Hh}$ morphogen controls a variety of conserved functions in invertebrates and vertebrates and that the dysregulation of the Hh pathway promotes developmental defects but also contributes to several cancer types, our study opens new perspectives to investigate the contribution of the EV-mediated Hh signaling to such physiological and pathological processes.

\section{STAR $\star$ METHODS}

Detailed methods are provided in the online version of this paper and include the following:

- KEY RESOURCES TABLE

- RESOURCE AVAILABILITY

O Lead contact

○ Materials availability

O Data and code availability

- EXPERIMENTAL MODEL AND SUBJECT DETAILS

- METHOD DETAILS

Establishment of promL2xsgRNA conditional mutant

Antibody Generation

O Extraction and analyzis of promL2xsgRNA by WB

$O$ Immunohistochemistry and fixed tissue imaging

O Adult wing preparation

○ Transmission Electron Microscopy (TEM)

O Live imaging

O Manual tracking of extracellular vesicles

- QUANTIFICATION AND STATISTICAL ANALYSIS

\section{SUPPLEMENTAL INFORMATION}

Supplemental information can be found online at https://doi.org/10.1016/j. cub.2021.11.023.

\section{ACKNOWLEDGMENTS}

We thank Ph. Vernier and A. Plessis for insightful discussions and critical reading of the manuscript; C. Dahmann, X., D. Godt, K. Yu, the Developmental Studies Hybridoma Bank, the Vienna Drosophila RNAi Center, Drosophila Genetics Resource Center, and Bloomington stock centers for reagents; Vincent Fraisier from the Imaging platform UMR144; and the Cell and Tissue Imaging (PICT-IBISA), Institut Curie, member of the French National Research Infrastructure France-Biolmaging (ANR10-INBS-04). This work was supported by the French Government (National Research Agency [ANR]) through the Investments for the Future LABEX SIGNALIFE (ANR-11-LABX-0028-01), LabEx CelTisPhyBio (ANR-11-LABX-0038), and ANR (ANR-15-CE13-0002-01); Ligue
Contre le Cancer 'Equipe labellisée 2016' to P.P.T.; and the Fondation pour la Recherche Médicale (DEQ201110421324).

\section{AUTHOR CONTRIBUTIONS}

Conceptualization, G.D.; methodology, I.H., M.R., L.S., E.P., L.R., and G.D.; software, A.-S.M.; formal analysis, I.H., A.-S.M., and G.D.; investigation, I.H., M.R., E.P., L.R., and G.D.; resources, R.B., P.P.T., and G.R.; writing - original draft, G.D.; writing - review \& editing, R.B., P.P.T., G.R., and G.D.; supervision, G.D.; funding acquisition, G.R. and P.P.T.

\section{DECLARATION OF INTERESTS}

The authors declare no competing interests.

\section{INCLUSION AND DIVERSITY}

The author list of this paper includes contributors from the location where the research was conducted who participated in the data collection, design, analysis, and/or interpretation of the work.

Received: November 23, 2020

Revised: August 12, 2021

Accepted: November 10, 2021

Published: December 9, 2021

\section{REFERENCES}

1. Briscoe, J., and Thérond, P.P. (2013). The mechanisms of Hedgehog signalling and its roles in development and disease. Nat. Rev. Mol. Cell Biol. 14, 416-429.

2. Porter, J.A., Young, K.E., and Beachy, P.A. (1996). Cholesterol modification of hedgehog signaling proteins in animal development. Science 274, 255-259.

3. Pepinsky, R.B., Zeng, C., Wen, D., Rayhorn, P., Baker, D.P., Williams, K.P., Bixler, S.A., Ambrose, C.M., Garber, E.A., Miatkowski, K., et al. (1998). Identification of a palmitic acid-modified form of human Sonic hedgehog. J. Biol. Chem. 273, 14037-14045.

4. van Niel, G., D’Angelo, G., and Raposo, G. (2018). Shedding light on the cell biology of extracellular vesicles. Nat. Rev. Mol. Cell Biol. 19, 213-228.

5. Callejo, A., Bilioni, A., Mollica, E., Gorfinkiel, N., Andrés, G., Ibáñez, C., Torroja, C., Doglio, L., Sierra, J., and Guerrero, I. (2011). Dispatched mediates Hedgehog basolateral release to form the long-range morphogenetic gradient in the Drosophila wing disk epithelium. Proc. Natl. Acad. Sci. USA 108, 12591-12598.

6. Ayers, K.L., Gallet, A., Staccini-Lavenant, L., and Thérond, P.P. (2010). The long-range activity of Hedgehog is regulated in the apical extracellular space by the glypican Dally and the hydrolase Notum. Dev. Cell 18, 605-620.

7. D’Angelo, G., Matusek, T., Pizette, S., and Thérond, P.P. (2015). Endocytosis of Hedgehog through dispatched regulates long-range signaling. Dev. Cell 32, 290-303.

8. Matusek, T., Wendler, F., Polès, S., Pizette, S., D’Angelo, G., Fürthauer, M., and Thérond, P.P. (2014). The ESCRT machinery regulates the secretion and long-range activity of Hedgehog. Nature 516, 99-103.

(D) Magnified area of $z$ projections of 167 plans, spaced $1 \mu \mathrm{m}$ apart, displaying a XY view of the A compartment of $h h>$ Hh-RFP; PromL-GFP disc recorded every 3 min for 90 min. Bottom: magnification of the inset shows examples of Hh/PromL-containing EVs (white circles) or Hh-containing EVs (yellow circles). Pink circles delimited the membrane of squamous cells.

(E) Histogram of $\mathrm{Hh} /$ PromL-EVs or Hh-EVs counted in the A compartment at different times and in different regions $(\mathrm{n}=894)$.

(F) Frames from Video S2 of $h h>H h$-RFP; PromL-GFP disc at the indicated time points.

(G) The travel distance of $\mathrm{Hh} /$ PromL-EVs (white arrowheads) gradually increased with time and is of $10 \mu \mathrm{m}$ in $80 \mathrm{~min}$ for the shown vesicle.

The manual tracking of EVs was performed in the boxed region in (C). Scale bar, $0.2 \mu \mathrm{m}$ (A and B); $20 \mu \mathrm{m}$ ( $\mathrm{C}$ and F); $5 \mu \mathrm{m}$ ( D and F). See also Figures S4 and S5 and Video S3. 


\section{$\infty$ CellPress}

\section{Current Biology}

9. Gradilla, A.-C., González, E., Seijo, I., Andrés, G., Bischoff, M., GonzálezMendez, L., Sánchez, V., Callejo, A., Ibáñez, C., Guerra, M., et al. (2014). Exosomes as Hedgehog carriers in cytoneme-mediated transport and secretion. Nat. Commun. 5, 5649.

10. Vyas, N., Walvekar, A., Tate, D., Lakshmanan, V., Bansal, D., Lo Cicero, A., Raposo, G., Palakodeti, D., and Dhawan, J. (2014). Vertebrate Hedgehog is secreted on two types of extracellular vesicles with different signaling properties. Sci. Rep. 4, 7357.

11. Ramírez-Weber, F.A., and Kornberg, T.B. (1999). Cytonemes: cellular processes that project to the principal signaling center in Drosophila imaginal discs. Cell 97, 599-607.

12. Zhang, Y., Bulkley, D.P., Xin, Y., Roberts, K.J., Asarnow, D.E., Sharma, A., Myers, B.R., Cho, W., Cheng, Y., and Beachy, P.A. (2018). Structural basis for cholesterol transport-like activity of the Hedgehog receptor Patched. Cell 175, 1352-1364.e14.

13. Bischoff, M., Gradilla, A.-C., Seijo, I., Andrés, G., Rodríguez-Navas, C., González-Méndez, L., and Guerrero, I. (2013). Cytonemes are required for the establishment of a normal Hedgehog morphogen gradient in Drosophila epithelia. Nat. Cell Biol. 15, 1269-1281.

14. Matusek, T., Marcetteau, J., and Thérond, P.P. (2020). Functions of Wnt and Hedgehog-containing extracellular vesicles in development and disease. J. Cell Sci. 133, jcs209742.

15. Röper, K., Corbeil, D., and Huttner, W.B. (2000). Retention of prominin in microvilli reveals distinct cholesterol-based lipid micro-domains in the apical plasma membrane. Nat. Cell Biol. 2, 582-592.

16. Janich, P., and Corbeil, D. (2007). GM1 and GM3 gangliosides highlight distinct lipid microdomains within the apical domain of epithelial cells. FEBS Lett. 581, 1783-1787.

17. Ikenouchi, J., Hirata, M., Yonemura, S., and Umeda, M. (2013). Sphingomyelin clustering is essential for the formation of microvilli. J. Cell Sci. 126, 3585-3592.

18. Martin-Belmonte, F., Gassama, A., Datta, A., Yu, W., Rescher, U., Gerke, V., and Mostov, K. (2007). PTEN-mediated apical segregation of phosphoinositides controls epithelial morphogenesis through Cdc42. Cell $128,383-397$

19. Marzesco, A.-M., Janich, P., Wilsch-Bräuninger, M., Dubreuil, V., Langenfeld, K., Corbeil, D., and Huttner, W.B. (2005). Release of extracellular membrane particles carrying the stem cell marker prominin-1 (CD133) from neural progenitors and other epithelial cells. J. Cell Sci. 118, 28492858.

20. Marzesco, A.-M., Wilsch-Bräuninger, M., Dubreuil, V., Janich, P., Langenfeld, K., Thiele, C., Huttner, W.B., and Corbeil, D. (2009). Release of extracellular membrane vesicles from microvilli of epithelial cells is enhanced by depleting membrane cholesterol. FEBS Lett. 583, 897-902.

21. Corbeil, D., Fargeas, C.A., and Huttner, W.B. (2001). Rat prominin, like its mouse and human orthologues, is a pentaspan membrane glycoprotein. Biochem. Biophys. Res. Commun. 285, 939-944.

22. Florek, M., Bauer, N., Janich, P., Wilsch-Braeuninger, M., Fargeas, C.A., Marzesco, A.-M., Ehninger, G., Thiele, C., Huttner, W.B., and Corbeil, D. (2007). Prominin-2 is a cholesterol-binding protein associated with apical and basolateral plasmalemmal protrusions in polarized epithelial cells and released into urine. Cell Tissue Res. 328, 31-47.

23. Demontis, F., and Dahmann, C. (2007). Apical and lateral cell protrusions interconnect epithelial cells in live Drosophila wing imaginal discs. Dev. Dyn. 236, 3408-3418.

24. Morin, X., Daneman, R., Zavortink, M., and Chia, W. (2001). A protein trap strategy to detect GFP-tagged proteins expressed from their endogenous loci in Drosophila. Proc. Natl. Acad. Sci. USA 98, 15050-15055.

25. D’Alterio, C., Tran, D.D.D., Yeung, M.W.Y.A., Hwang, M.S.H., Li, M.A., Arana, C.J., Mulligan, V.K., Kubesh, M., Sharma, P., Chase, M., et al. (2005). Drosophila melanogaster Cad99C, the orthologue of human Usher cadherin PCDH15, regulates the length of microvilli. J. Cell Biol. $171,549-558$
26. Schlichting, K., Wilsch-Bräuninger, M., Demontis, F., and Dahmann, C. (2006). Cadherin Cad99C is required for normal microvilli morphology in Drosophila follicle cells. J. Cell Sci. 119, 1184-1195.

27. Zheng, H., Zhang, Y., Chen, Y., Guo, P., Wang, X., Yuan, X., Ge, W., Yang, R., Yan, Q., Yang, X., and Xi, Y. (2019). Prominin-like, a homolog of mammalian CD133, suppresses di Ip6 and TOR signaling to maintain body size and weight in Drosophila. FASEB J. 33, 2646-2658.

28. Thamm, K., Šimaitè, D., Karbanová, J., Bermúdez, V., Reichert, D., Morgenstern, A., Bornhäuser, M., Huttner, W.B., Wilsch-Bräuninger, M. and Corbeil, D. (2019). Prominin-1 (CD133) modulates the architecture and dynamics of microvilli. Traffic 20,39-60.

29. Kuwabara, P.E., and Labouesse, M. (2002). The sterol-sensing domain: multiple families, a unique role? Trends Genet. 18, 193-201.

30. Burke, R., Nellen, D., Bellotto, M., Hafen, E., Senti, K.A., Dickson, B.J., and Basler, K. (1999). Dispatched, a novel sterol-sensing domain protein dedicated to the release of cholesterol-modified hedgehog from signaling cells. Cell 99, 803-815.

31. Karbanová, J., Lorico, A., Bornhäuser, M., Corbeil, D., and Fargeas, C.A. (2018). Prominin-1/CD133: lipid raft association, detergent resistance, and immunodetection. Stem Cells Transl. Med. 7, 155-160.

32. van der Mark, V.A., de Waart, D.R., Ho-Mok, K.S., Tabbers, M.M., Voogt, H.W., Oude Elferink, R.P.J., Knisely, A.S., and Paulusma, C.C. (2014). The lipid flippase heterodimer ATP8B1-CDC50A is essential for surface expression of the apical sodium-dependent bile acid transporter (SLC10A2/ASBT) in intestinal Caco-2 cells. Biochim. Biophys. Acta 1842 (12 Pt A), 2378-2386.

33. Tanaka, K., Fujimura-Kamada, K., and Yamamoto, T. (2011). Functions of phospholipid flippases. J. Biochem. 149, 131-143.

34. Stapelbroek, J.M., Peters, T.A., van Beurden, D.H.A., Curfs, J.H.A.J., Joosten, A., Beynon, A.J., van Leeuwen, B.M., van der Velden, L.M., Bull, L., Oude Elferink, R.P., et al. (2009). ATP8B1 is essential for maintaining normal hearing. Proc. Natl. Acad. Sci. USA 106, 9709-9714.

35. Verhulst, P.M., van der Velden, L.M., Oorschot, V., van Faassen, E.E., Klumperman, J., Houwen, R.H.J., Pomorski, T.G., Holthuis, J.C.M., and Klomp, L.W.J. (2010). A flippase-independent function of ATP8B1, the protein affected in familial intrahepatic cholestasis type 1 , is required for apical protein expression and microvillus formation in polarized epithelial cells. Hepatology 51, 2049-2060.

36. Kumar, N., Zhao, P., Tomar, A., Galea, C.A., and Khurana, S. (2004). Association of villin with phosphatidylinositol 4,5-bisphosphate regulates the actin cytoskeleton. J. Biol. Chem. 279, 3096-3110.

37. Mahajan-Miklos, S., and Cooley, L. (1994). The villin-like protein encoded by the Drosophila quail gene is required for actin bundle assembly during oogenesis. Cell 78, 291-301.

38. Dubreuil, V., Marzesco, A.-M., Corbeil, D., Huttner, W.B., and WilschBräuninger, M. (2007). Midbody and primary cilium of neural progenitors release extracellular membrane particles enriched in the stem cell marker prominin-1. J. Cell Biol. 176, 483-495.

39. Nager, A.R., Goldstein, J.S., Herranz-Pérez, V., Portran, D., Ye, F., GarciaVerdugo, J.M., and Nachury, M.V. (2017). An actin network dispatches ciliary GPCRs into extracellular vesicles to modulate signaling. Cell 168, 252-263.e14.

40. Ha, T.S., Xia, R., Zhang, H., Jin, X., and Smith, D.P. (2014). Lipid flippase modulates olfactory receptor expression and odorant sensitivity in Drosophila. Proc. Natl. Acad. Sci. USA 111, 7831-7836.

41. Corbeil, D., Röper, K., Fargeas, C.A., Joester, A., and Huttner, W.B. (2001). Prominin: a story of cholesterol, plasma membrane protrusions and human pathology. Traffic 2, 82-91.

42. Strutt, H., Thomas, C., Nakano, Y., Stark, D., Neave, B., Taylor, A.M., and Ingham, P.W. (2001). Mutations in the sterol-sensing domain of Patched suggest a role for vesicular trafficking in Smoothened regulation. Curr. Biol. 11, 608-613.

43. Gallet, A., Rodriguez, R., Ruel, L., and Therond, P.P. (2003). Cholesterol modification of hedgehog is required for trafficking and movement, 


\section{Current Biology}

\section{Article}

revealing an asymmetric cellular response to hedgehog. Dev. Cell 4, 191-204.

44. Duncan, D.M., Burgess, E.A., and Duncan, I. (1998). Control of distal antennal identity and tarsal development in Drosophila by spineless-aristapedia, a homolog of the mammalian dioxin receptor. Genes Dev. 12, 1290-1303.

45. Friggi-Grelin, F., Rabouille, C., and Therond, P. (2006). The cis-Golgi Drosophila GMAP has a role in anterograde transport and Golgi organization in vivo, similar to its mammalian ortholog in tissue culture cells. Eur. J. Cell Biol. 85, 1155-1166.

46. Tanimoto, H., Itoh, S., ten Dijke, P., and Tabata, T. (2000). Hedgehog creates a gradient of DPP activity in Drosophila wing imaginal discs. Mol. Cell 5, 59-71.
47. Port, F., and Bullock, S.L. (2016). Augmenting CRISPR applications in Drosophila with tRNA-flanked sgRNAs. Nat. Methods 13, 852-854.

48. Groth, A.C., Fish, M., Nusse, R., and Calos, M.P. (2004). Construction of transgenic Drosophila by using the site-specific integrase from phage phiC31. Genetics 166, 1775-1782.

49. Mastronarde, D.N. (1997). Dual-axis tomography: an approach with alignment methods that preserve resolution. J. Struct. Biol. 120, 343-352.

50. Hurbain, I., Romao, M., Bergam, P., Heiligenstein, X., and Raposo, G. (2017). Analyzing Lysosome-Related Organelles by Electron Microscopy. Methods Mol. Biol. 1594, 43-71.

51. Slot, J.W., and Geuze, H.J. (2007). Cryosectioning and immunolabeling. Nat. Protoc. 2, 2480-2491. 


\section{STAR $\star$ METHODS}

\section{KEY RESOURCES TABLE}

\begin{tabular}{|c|c|c|}
\hline REAGENT or RESOURCE & SOURCE & IDENTIFIER \\
\hline \multicolumn{3}{|l|}{ Antibodies } \\
\hline Mouse anti-En & $\begin{array}{l}\text { Development Studies Hybridoma } \\
\text { Bank University of lowa }\end{array}$ & DSHB Cat\# 4D9 \\
\hline rabbit anti-En & Santa Cruz & Cat\# Sc-28640; RRID: AB_640146 \\
\hline mouse anti-Ptc & Strutt et al. ${ }^{42}$ & $\mathrm{~N} / \mathrm{A}$ \\
\hline chicken anti- $\beta$ gal & Gen Tex & Cat\# GTX77365; RRID: AB_379834 \\
\hline rabbit anti-Hh & Gallet et al. ${ }^{43}$ & N/A \\
\hline rabbit anti-Hh & From T. Kornberg (UCSF) & $\mathrm{N} / \mathrm{A}$ \\
\hline mouse anti-Cut & $\begin{array}{l}\text { Development Studies Hybridoma } \\
\text { Bank University of lowa }\end{array}$ & DSHB Cat\# 2B10; RRID: AB_528186 \\
\hline mouse anti-Wg & $\begin{array}{l}\text { Development Studies Hybridoma } \\
\text { Bank University of lowa }\end{array}$ & DSHB Cat\# 4D4; RRID: AB_528512 \\
\hline guinea-pig anti-PromL & This paper & N/A \\
\hline mouse anti-DII & Duncan et al. ${ }^{44}$ & $\mathrm{~N} / \mathrm{A}$ \\
\hline rabbit anti-aPKC & Sigma & Cat\# SAB4502355; RRID: AB_10746417 \\
\hline rat anti-DE cadherin & $\begin{array}{l}\text { Development Studies Hybridoma } \\
\text { Bank University of lowa }\end{array}$ & DSHB Cat\# 4D4 \\
\hline mouse anti-Dlg & $\begin{array}{l}\text { Development Studies Hybridoma } \\
\text { Bank University of lowa }\end{array}$ & DSHB Cat\# 4F3 \\
\hline mouse anti-Arm & $\begin{array}{l}\text { Development Studies Hybridoma } \\
\text { Bank University of lowa }\end{array}$ & DSHB Cat\# N27A1 \\
\hline mouse anti-GFP & Roche & Cat\# 11814460001; RRID: AB_390913 \\
\hline rabbit anti-GFP & Molecular Probes & Cat\#A21312; RRID: AB_221478 \\
\hline rabbit anti-Cad99c & D'Alterio et al. ${ }^{25}$ & $\mathrm{~N} / \mathrm{A}$ \\
\hline rabbit anti-Caspase 3 & Cell Signaling & Cat\#9662; RRID: AB_331439 \\
\hline rabbit anti-dGMAP & Friggi-Grelin et al. ${ }^{45}$ & N/A \\
\hline goat anti-mouse, Alexa 488 & Thermo Fisher Scientific & Cat\#A11001; RRID: AB_2534069 \\
\hline goat anti-rabbit, Alexa 488 & Thermo Fisher Scientific & Cat\#A11034; RRID: AB_2576217 \\
\hline goat anti-guinea-pig, Alexa 488 & Thermo Fisher Scientific & Cat\#A11073; RRID: AB_2534117 \\
\hline goat anti-rabbit, Alexa 546 & Thermo Fisher Scientific & Cat\#A11035; RRID: AB_2534093 \\
\hline goat anti-rat, Alexa 546 & Thermo Fisher Scientific & Cat\#A11081; RRID: AB_2534125 \\
\hline goat anti-mouse, Alexa 647 & Thermo Fisher Scientific & Cat\#A21236; RRID: AB_2535805 \\
\hline goat anti-rat, Alexa 647 & Thermo Fisher Scientific & Cat\#A21246; RRID, AB_141778 \\
\hline goat anti-guinea-pig, Alexa 647 & Thermo Fisher Scientific & Cat\#A21450; RRID, AB_2735091 \\
\hline donkey anti-chicken, Суз & Jackson Immuno Research & Cat\#703-165-155; RRID: AB_2340363 \\
\hline \multicolumn{3}{|c|}{ Chemicals, peptides, and recombinant proteins } \\
\hline Penicillin/Streptomycin & GIBCO & CAT\#15140 \\
\hline Schneider's Drosophila Medium & GIBCO & CAT\#21720-024 \\
\hline fetal bovine serum & GIBCO & CAT\#10500 \\
\hline CellMask & Molecular Probes & CAT\#C10046 \\
\hline VECTASHIELD anti-fade mounting media & Vector Laboratories & CAT\#H-1000 \\
\hline paraformaldehyde $16 \%$ & Electron Microscopy Science & CAT\#15710 \\
\hline glutaraldehyde $25 \%$ & Electron Microscopy Science & CAT\#16220 \\
\hline osmium tetroxide $4 \%$ & Electron Microscopy Science & CAT\#19190 \\
\hline potassium ferrocyanide & Sigma & САT\#Р3289 \\
\hline sodium cacodylate & Electron Microscopy Science & САT\#2300 \\
\hline
\end{tabular}


Current Biology

\begin{tabular}{|c|c|c|}
\hline \multicolumn{3}{|l|}{ Continued } \\
\hline REAGENT or RESOURCE & SOURCE & IDENTIFIER \\
\hline lead Citrate & Electron Microscopy Science & CAT\#11300 \\
\hline uranylacetate & LFG & N/A \\
\hline gelatin & Electron Microscopy Science & CAT\#70102 \\
\hline Protein A Gold & $\begin{array}{l}\text { Cell Microscopy Center (CMC), } \\
\text { Utrecht University }\end{array}$ & N/A \\
\hline Euparal & Carl ROTH & CAT\#7356.1 \\
\hline Triton X-100 & Euromedex & CAT\#2000-C \\
\hline Halt Protease Phosphatase Inhibitors Cocktail & Thermo Fisher Scientific & CAT\#78440 \\
\hline Ni-NTA resin & Generon & CAT\#SUPER-NINTA25 \\
\hline Voltalef $10 \mathrm{~S}$ oil & VWR Chemicals & CAT\#24627.188 \\
\hline \multicolumn{3}{|l|}{ Critical commercial assays } \\
\hline StabyExpress $\mathrm{T} 7$ expression kit & Eurogentec & CAT\#GE-SET7-0707 \\
\hline Standard membrane Kit & YSI & SKU: 098094 \\
\hline Embed 812 Embedding kit & Electron Microscopy Science & CAT\#14120 \\
\hline \multicolumn{3}{|l|}{ Experimental models: Organisms/strains } \\
\hline D. melanogaster: $\mathrm{w}^{1118}$ & $\begin{array}{l}\text { Bloomington Drosophila } \\
\text { Stock Center }\end{array}$ & $\begin{array}{l}\text { FlyBase: FBal0018157; } \\
\text { RRID: BDSC_3605 }\end{array}$ \\
\hline D. melanogaster: ap-Gal4 & $\begin{array}{l}\text { Bloomington Drosophila } \\
\text { Stock Center }\end{array}$ & $\begin{array}{l}\text { FlyBase: FBti0002785; } \\
\text { RRID: BDSC_3041 }\end{array}$ \\
\hline D. melanogaster: $h$ h-Gal4 & Tanimoto et al. ${ }^{46}$ & FlyBase ID: FBti0017278 \\
\hline D. melanogaster: UAS-Dcr 2 & $\begin{array}{l}\text { Bloomington Drosophila } \\
\text { Stock Center }\end{array}$ & $\begin{array}{l}\text { FlyBase ID: FBtp0036672; } \\
\text { RRID: BDSC_24650 }\end{array}$ \\
\hline D. melanogaster: disp ${ }^{5037707}$ & Burke et al. ${ }^{30}$ & $\begin{array}{l}\text { FlyBase: FBst0053711; } \\
\text { RRID: BDSC_53711 }\end{array}$ \\
\hline D. melanogaster: promL ${ }^{\Delta 1-3}$ & Zheng et al. ${ }^{27}$ & $\mathrm{~N} / \mathrm{A}$ \\
\hline D. melanogaster: UAS-Hh-RFP & $\begin{array}{l}\text { X. Lin (Cincinnati Children's } \\
\text { Hospital Medical Center) }\end{array}$ & $\mathrm{N} / \mathrm{A}$ \\
\hline$v k g^{G 454}(G F P-V k g)$ & Morin et al. ${ }^{24}$ & $\mathrm{~N} / \mathrm{A}$ \\
\hline D. melanogaster: UAS-PromL-GFP & Demontis and Dahmann ${ }^{23}$ & $\mathrm{~N} / \mathrm{A}$ \\
\hline D. melanogaster: UAS-ATP8B & Vienna Drosophila Resource Center & VDRC: v102648 \\
\hline D. melanogaster:UAS-PromL & Vienna Drosophila Resource Center & VDRC: v102612 \\
\hline D. melanogaster: UAS-PromL & Vienna Drosophila Resource Center & VDRC: v51957 \\
\hline D. melanogaster: UAS-Fim & Vienna Drosophila Resource Center & VDRC: v48028 \\
\hline D. melanogaster: UAS-Fim & Vienna Drosophila Resource Center & VDRC: v48029 \\
\hline D. melanogaster: UAS-Fim & Vienna Drosophila Resource Center & VDRC: v47511 \\
\hline D. melanogaster: UAS-Fim & Vienna Drosophila Resource Center & VDRC: v47514 \\
\hline D. melanogaster: UAS-Qua & Vienna Drosophila Resource Center & VDRC: v100856 \\
\hline D. melanogaster: UAS-Qua & Vienna Drosophila Resource Center & VDRC: v27623 \\
\hline \multicolumn{3}{|l|}{ Oligonucleotides } \\
\hline $\begin{array}{l}\text { Forward primer to amplify PromL region } \\
\text { (a.a.53-214): CACCGGTACCATGGAC } \\
\text { GCCCAGGCTGATGCAGATCCCG } \\
\text { GGAGCTGGCGC }\end{array}$ & This paper & $\mathrm{N} / \mathrm{A}$ \\
\hline $\begin{array}{l}\text { Reverse primer to amplify PromL region } \\
\text { (a.a.53-214): AAGTCTAGAACAGAA } \\
\text { GCGCCGCTGAGCATCGTGTTTACT }\end{array}$ & This paper & $\mathrm{N} / \mathrm{A}$ \\
\hline $\begin{array}{l}\text { Forward primer to amplify PromL region } \\
\text { (a.a.556-851): CACCGGTACCATGGTA } \\
\text { ACCTACCAGGGTGCCTGTGCA CCACTG }\end{array}$ & This paper & $\mathrm{N} / \mathrm{A}$ \\
\hline $\begin{array}{l}\text { Reverse primer to amplify PromL region } \\
\text { (a.a.556-851): AAGTCTAGAGGGATCC } \\
\text { ACGATACGGTGGCAAATCAAATC }\end{array}$ & This paper & $\mathrm{N} / \mathrm{A}$ \\
\hline
\end{tabular}




\section{Current Biology}

\begin{tabular}{|c|c|c|}
\hline \multicolumn{3}{|l|}{ Continued } \\
\hline REAGENT or RESOURCE & SOURCE & IDENTIFIER \\
\hline $\begin{array}{l}\text { Forward primer targeting the exon } 1 \text { of the } \\
\text { promL gene: CGGCCCGGGTTCGATTCC } \\
\text { CGGCCGATGCAtaggcgacaaatagcctaccG } \\
\text { TITCAGAGCTATGCTGGAAAC (lower cases } \\
\text { for CRISPR targeted the exon 1) }\end{array}$ & This paper & $\mathrm{N} / \mathrm{A}$ \\
\hline $\begin{array}{l}\text { Reverse primer targeting the exon } 8 \text { of the } \\
\text { promL gene: ATTITAACTTGCTATTCTAG } \\
\text { CTCTAAAACtgatagaaacgttgtcagcCTGCA } \\
\text { CCAGCCGGGAATCGAACC (lower cases } \\
\text { for CRISPR targeted the exon 8) }\end{array}$ & This paper & $\mathrm{N} / \mathrm{A}$ \\
\hline \multicolumn{3}{|l|}{ Recombinant DNA } \\
\hline cDNA UFO07496 & $\begin{array}{l}\text { Drosophila Genomics } \\
\text { Resource Center }\end{array}$ & DGRC; \#1642171 \\
\hline pStaby & Eurogentec & CAT\#GE-SET7-0707 \\
\hline Plasmid: pCFD6 & Port and Bullock ${ }^{47}$ & $\mathrm{~N} / \mathrm{A}$ \\
\hline \multicolumn{3}{|l|}{ Software and algorithms } \\
\hline Excel & Microsoft & https://www.microsoft.com \\
\hline Fiji & $\mathrm{NIH}$ & https://imagej.net \\
\hline MetaMorph & Molecular Devices & https://www.moleculardevices.com \\
\hline GraphPad Prism & GraphPad Software & $\begin{array}{l}\text { http://www.graphpad.com/ } \\
\text { scientific-software/prism }\end{array}$ \\
\hline iTEM & Soft Imaging System & https://www.olympus-sis.com \\
\hline IMOD & University of Colorado & https://bio3d.colorado.edu \\
\hline \multicolumn{3}{|l|}{ Other } \\
\hline Ni-NTA resin & Thermo Fisher Scientific & \#88223 \\
\hline Glass bottom dish & Mat Tek Corporation & P35G-1.5-1.4-C \\
\hline
\end{tabular}

\section{RESOURCE AVAILABILITY}

\section{Lead contact}

Further information and requests for resources and reagents should be directed to and will be fulfilled by the Lead Contact, Gisela D’Angelo (gisela.dangelo@curie.fr).

\section{Materials availability}

Plasmids, Drosophila strains, and anti-PromL antibodies used and generated in this study are available upon from the Lead Contact without restriction.

Data and code availability

- All data reported in this paper will be shared by the lead contact upon request.

- This paper does not report original code.

- Any additional information required to reanalyze the data reported in this paper is available from the lead contact upon request.

\section{EXPERIMENTAL MODEL AND SUBJECT DETAILS}

Drosophila melanogaster strains were raised on standard media (cornmeal, yeast, molasses, and agar) at $22^{\circ} \mathrm{C}$, and experimental crosses at $25^{\circ} \mathrm{C}$. $w^{1118}$, apGal4 (II), hhGal4 (III), UAS-Dicer2 (III) from the Bloomington Stock Center and are listed in Flybase (http://flybase.org:80/) and, promL ${ }^{\Delta 3-1}$ mutant $^{27}$ kindly provided by K. Yu (Korea Institute of Science and Technology), proteintrap vkg ${ }^{G 454}$ (GFP-Vkg), ${ }^{24}$ UAS-Cas9; hh-Gal4 from S. Bullock (MRC Laboratory of Molecular Biology, Cambridge), UAS-Hh-RFP (II) from X. Lin (Cincinnati Children's Hospital Medical Center), UAS-PromL-GFP (III) from C. Dahmann (Dresden University of Technology). disp ${ }^{\text {SO37707 }}$ is a null allele. ${ }^{30}$ The UAS-RNAi lines against ATP8B (ATP8B ${ }^{102648 K K}$ ), PromL (PromL ${ }^{102612 K K}$, PromL $^{51957 G D}$ ), Fimbrin (Fim ${ }^{46028 G D}$, Fim ${ }^{46029 G D}$, Fim ${ }^{47511 G D}$, Fim ${ }^{47514 G D}$ ), Quail (Qua ${ }^{100856 K K}$, Qua ${ }^{27623 G D}$ ) were from Vienna Drosophila Resource Center. Recombinant chromosomes were created for dpp-lacZ; promL ${ }^{\Delta 3-1}$, ap-Gal4;UAS-Dicer2, and UAS-Hh-RFP; UAS-PromLGFP by classical genetic techniques. All stocks were raised at $25^{\circ} \mathrm{C}$, unless otherwise mentioned. 


\section{Current Biology Article}

\section{METHOD DETAILS}

Establishment of promL2xsgRNA conditional mutant

To edit the genome specifically in wing imaginal tissues, CRISPR/Cas9 system was used. In order to generate a deletion of promL gene, the gRNA targeting the exon 1 and exon 8 of the promL was synthesized using a forward primer $\left(5^{\prime}\right.$-CGGCCCGGGTCGATT CCCGGCCGATGCAtaggcgacaaatagcctaccGTTTCAGAGCTATGCTGGAAAC $-3^{\prime}$, lower case for CRISPR targeted the exon 1) and a reverse primer (5'ATTITAACTTGCTATTTCTAGCTCTAAAACtgatagaaacgttgtcagcCTGCACCAGCCGGGAATCGAACC -3', lower case for CRISPR targeted the exon 8). Both gRNAs targeting PromL were cloned in Bbsl site of $p C F D 6$ vector as previously described. ${ }^{47}$ Transgenic fly lines were generated by standard procedures, and were integrated on the second chromosome using the PhiC31-integrase-mediated transformation. ${ }^{48}$ The transgenic flies expressing promL gRNAs (promL2xsgRNA) were crossed with UAS-Cas9; hhGa/4 individuals at $25^{\circ} \mathrm{C}$. The wing imaginal discs from the progeny were collected, fixed and immunostained.

\section{Antibody Generation}

cDNAs encoding two different regions (aa 53-214; aa 556-851) of the D. melanogaster PromL full length cDNA (UFO07496 clone; Drosophila Genomics Resource Center), were cloned into pStaby1.2 vector (Eurogentec) such as the peptides were tagged C-terminally with $6 \mathrm{xH}$ is. Both $6 \mathrm{xH}$ is peptides were expressed in E. coli using StabyExpress 77 expression kit, (Eurogentec) and purified on Ni-NTA resin (Invitrogen) by standard protocol. The peptides were soluble and injected individually into two guinea pigs (Eurogentec). To increase the antigenicity the obtained antisera were mixed, and the antisera were screened for antibodies against PromL using immunostaining of wing imaginal discs.

\section{Extraction and analyzis of promL2xsgRNA by WB}

10 third-instar larvae of each genotype were crushed and lysed on ice in lysis buffer $(20 \mathrm{mM}$ Tris- $\mathrm{HCL} \mathrm{pH}, 150 \mathrm{mM} \mathrm{NaCl}$ and $1 \%$ Triton) supplemented with phosphatase and protease inhibitors. The lysates were resolved by SDS-PAGE and western blotting were performed with antibodies against PromL (1/5000) and against GMAP ${ }^{45}(1 / 2500)$ for loading gel control.

\section{Immunohistochemistry and fixed tissue imaging}

Third-instar wing imaginal discs were dissected and immunostained as previously described. ${ }^{7}$ Briefly, imaginal discs were dissected in PBS and fixed in 4\% paraformaldehyde (PFA, Electron Microscopy Science - EMS) diluted in PBS for 20 minutes at room temperature. Fixed tissues were washed and permeabilised three times for 10 minutes with PBS-T (PBS, $0.1 \%$ Triton X-100, Euromedex), and incubated with primary antibodies overnight at $4^{\circ} \mathrm{C}$. After washing in PBS-T three times, discs were incubated with secondary antibody 1 hat room temperature, and washed in PBS-T three times, rinsed in PBS before mounting in Vectashield antifade mounting media (Vector Laboratories). Antibodies were used as follows: mouse anti-En (1:1000, Development Studies Hybridoma Bank University of lowa DSHB), rabbit anti-En (1:1000, Santa Cruz), mouse anti-Ptc ${ }^{42}$ (1/400), chicken anti-Bgal (1:1000, Gen Tex), affinity-purified rabbit "Calvados" polyclonal anti-Hh ${ }^{43}$ (1:200), mouse anti-Cut (1:100, DSHB), mouse anti-Wg (1:50, DSHB), guinea pig anti-PromL (1:150, this study), mouse anti DII ${ }^{44}(1: 100)$, rabbit anti-aPKC (1:500, Santa Cruz), rat anti-DE-cadherin (1:50, DSHB), mouse anti-Dlg (1:100, DSHB); mouse anti-Arm (1:100,DSHB), mouse anti-GFP (1:1000, Roche), rabbit anti-Cad99c ${ }^{25}$ (1:1000, D. Godt, University of Toronto), rabbit anti-Caspase 3 (1:500, Cell Signaling). Fluorescent secondary antibodies were anti-mouse Alexa Fluor 488, anti-mouse Alexa 647, anti-rabbit Alexa 488, anti-rabbit Alexa 546, anti-rat Alexa 546, anti-rat Alexa 647, anti-guinea pig 488, anti-guinea pig 647 (1:250, Thermo Fisher Scientific), and anti-chicken Cy3 (1:100, Jackson Immuno Reaseach). Images were obtained with a Leica TCS SP5 or SP8 confocal microscope and processed with Image J. $X Y$ and $Z$-sections are single sections captured at the appropriate level (apical, subapical, or lateral). Data analyzis, curve fitting, and presentation were done with ImageJ, Excel and GraphPad Prim software.

\section{Adult wing preparation}

Adult flies were collected in ethanol. Wings were removed, mounted in Euparal Medium (Carl ROTH). Bright-field images were taken with a Leica Axioplan2 microscope (objective, $\times 5$; Plan NEOFLUAR; NA $=0.15$ ) equipped with a Leica DFC490 digital camera.

\section{Transmission Electron Microscopy (TEM)}

Third-instar wing imaginal discs were dissected in Schneider's Drosophila medium (GIBCO) supplemented with $10 \%$ heat-inactivated fetal bovine serum (FBS, GIBCO), penicillin $(100 \mathrm{U} / \mathrm{ml})$ and streptomycin $(100 \mu \mathrm{g} / \mathrm{ml})$, and fixed in $1.5 \%$ glutaraldehyde (EMS) in $0.075 \mathrm{M}$ cacodylate buffer ( $\mathrm{pH} 7,2, \mathrm{EMS}$ ) overnight at $4^{\circ} \mathrm{C}$, and post fixed in $1 \%$ osmium (EMS) $-1.5 \%$ potassium ferrocyanide (Sigma). The discs were then dehydrated in increasing concentrations of ethanol solutions, positioned perpendicularly (with the apical surface facing the top) and embedded in EPON (EMS). Ultrathin EPON sections (40-60 $\mu \mathrm{m}$-thick sections depending on the genotype and the size of the wing discs), along the A/P axis were collected on formvar-coated slot grids and contrasted with uranyl acetate (LFG) and lead citrate (EMS). To determine the origin of EVs, serial sections of $65 \mathrm{~nm}$ thickness (over $260 \mathrm{~nm}$ ) were collected from wt wing discs. Electron micrographs were acquired on a Tecnai Spirit transmission electron microscope (Tecnai Spirit, Thermo Fischer Scientific) equipped with 4k CCD camera (Quemesa, Soft Imaging System). Images were taken along the A/P axis enabling the visualization of the entire discs.

For Electron Tomography $300 \mathrm{~nm}$ thick sections were randomly labeled on the 2 sides with protein A-gold 15-nm (Cell Microscopy Center - CMC -, Utrecht University and poststained with $2 \%$ uranylacetate (LFG). Tilt series (angular range from $-60^{\circ}$ to $+60^{\circ}$ with 


\section{$\infty$ CellPress}

\section{Current Biology}

$1^{\circ}$ increments) were recorded by using EMtools (TVIPS) on a 200-kV transmission electron microscope (Tecnai 20 LaB $_{6}$, Thermo Fischer Scientific) and used for reconstructing tomograms. Projection images (2024 $\times 2024$ pixels) were recorded with a CCD camera (Temcam F416; TVIPS). Alignment of the tilt series and tomogram computing (resolution-weighted back-projection) were carried out by using the eTomo (IMOD, University of Colorado). The $15 \mathrm{~nm}$ gold particles at the surface of the sections were used as fiducial markers. Manual contouring of the tomograms was done by using the IMOD program. ${ }^{49}$

For Immunoelectron Microscopy (IEM), third-instar wing imaginal discs were dissected in Schneider's Drosophila medium (GIBCO) supplemented with $10 \%$ heat-inactivated FBS (GIBCO), penicillin (100 U/ml) and streptomycin (100 $\mu \mathrm{g} / \mathrm{ml})$, fixed in a mixture of $2 \%$ PFA (EMS) and 0,2\% glutaraldehyde (EMS) in a 0,1M phosphate buffer $\mathrm{pH} 7,4$ for $2 \mathrm{~h}$ at room temperature, followed by overnight incubation at $4^{\circ} \mathrm{C}$ in $1 \%$ PFA in phosphate buffer. Discs were very lightly stained with $1 \%$ Toluidine Blue and individually embedded in $15 \%$ gelatin (EMS), and processed for ultracryomicrotomy as described. ${ }^{50}$ Ultrathin sections $(60-80 \mathrm{~nm})$ were prepared with an ultracryomicrotome UC7 (Leica) and double labeling with rabbit anti- Hh (1/500, T. Kornberg, University of California, San Franscisco), and rabbit anti-GFP (1:120, Molecular Probes) were performed sequentially as described. ${ }^{51}$ Rabbit antibodies were recognized by protein A conjugated to 10 or $15 \mathrm{~nm}$ gold particles (protein A gold, CMC).

\section{Live imaging}

Third-instar wing imaginal discs were dissected in Schneider's Drosophila Medium (GIBCO) supplemented with 10\% heat-inactivated fetal bovine serum (GIBCO), Penicillin (100 units $\mathrm{ml}^{-1}$ ) and Streptomycin $\left(100 \mu \mathrm{g} \mathrm{ml}^{-1}\right)$ (Penicillin-Streptomycin, GIBCO). Two to four wing discs were placed on a glass bottom $35 \mathrm{~mm}$ dish (MatTek Corporation) with $10 \mu$ l of medium containing CellMask (deep red plasma membrane stain; 1:1000, Molecular Probes), covered with a permeable membrane (Standard membrane kit, YSI), and sealed around the membrane borders with oil 10S Voltalef (VWR Chemicals). Images were recorded using a Yokagawa CSU-W1 spinning head mounted on a Nikon TiE inverted microscope. The microscope was equipped with an EMCCD $1200 \times 1200$ Prime95B (Photometrics) and controlled by the Metamorph software (Molecular Devices). In most experiments, $z$ stacks at $1 \mu \mathrm{m}$ intervals were acquired every 3 min using a $40 \times$ NA 1.15 water immersion objective, but only the most in-focus planes were used for image analyzis. Images were processed with ImageJ. All movies were analyzed with Fiji and displayed at a rate of 7 frames per second.

Manual tracking of extracellular vesicles

EVs were tracked using the MTrackJ plugin of ImageJ. The tracking was performed in a summed z-projections taking into account 167 plans at $1 \mu \mathrm{m}$ intervals and recorded every 3 min within a $25 \mu \mathrm{m} \times 30 \mu \mathrm{m}$ delimited regions. Travel distances were analyzed within the indicated time-window, measured using the line tool in ImageJ and then calculated using the following formula:

$$
\text { distance }(a b)=\sqrt{(x b-x a) 2+(y b-y a) 2}
$$

where $(x a, y a)$ and $(x b, y b)$ are the coordinates of the initial and end points respectively.

\section{QUANTIFICATION AND STATISTICAL ANALYSIS}

The colocalization of PromL and $\mathrm{Hh}$ was measured on single $z$-sections within a region of interest (ROIs) of $10 \times 40 \mu \mathrm{m}$. The width $(10 \mu \mathrm{m})$ was centered on either side of the subapical marker E-cad. Manual thresholding was applied to each channel using ImageJ/Fij. The overlay of the two images enabled to determine the colocalization between Hh and PromL. The Hh signal overlapping with PromL (colocalized $\mathrm{Hh}$ ) was compared to the total $\mathrm{Hh}$ intensity within the ROI. The ratio between the two values was calculated. Where comparison between separate discs was required, fluorescence intensity was measured in regions of interest (ROIs) of identical sizes and shapes and drawn at equivalent locations within each disc and for all genotypes. Data represent mean \pm SEM .

To evaluate the strength of the relationship between microvilli length/number, Hh-PromL colocalization, number of cells expression $d p p$ and number of EVs was computed on the mean values obtained for each genotype. The correlation coefficient was determined between two variables at a time.

Different sections of TEM micrographs for the different genotypes were used to manually quantify the number of microvilli and EVs observed, except for wt discs for which serial sections were collected to identify the origin of EVs. Since the microvilli were often tilted, we measured their length from their tip to the planar cell surface with an angle of $90^{\circ} \mathrm{C}$ (Figure S4A). The EM analysis also revealed a different electron density between the content of EVs in the lumen and the cytoplasm of microvilli, excluding therefore a possible sectioning problem.

The diameter of EVs and ILVs was evaluated using iTEM software (Soft Imaging System, EMSIS GmbH, Germany). Data represent generally mean \pm SEM.

The presence of Hh, PromL or both on EVs in A compartment was estimated using the algorithm described below. Given the positions of the $x_{i}$ particles clicked in the red channel, the algorithm defines the particle as a vesicle if the maximum intensity in the blue channel $I_{b}$, in the vicinity of the radius $(r)$, is greater than a fixed threshold, such that:

$$
\max _{B\left(x_{i}, R\right)} I_{b}>T_{b} \text {, where } B\left(x_{i}, R\right) \text { is the ball of radius } r \text { and center } x_{i} \text {. }
$$




\section{Current Biology}

\section{Article}

The algorithm defines that the vesicle is also green on the same principle, based on the intensity on the green channel $I_{g}$, in the same vicinity:

$$
\max _{B\left(x_{i}, R\right)} I_{-} g>T_{g}
$$

We defined $r=5$ pixels, $T_{b}=800, T_{g}=170$, and manual validations were performed to obtain more accurate results. Data analyzis, curve fitting, and presentation were done with ImageJ, Excel and GraphPad Prism software. 
Current Biology, Volume 32

Supplemental Information

Microvilli-derived extracellular vesicles

carry Hedgehog morphogenic signals for

Drosophila wing imaginal disc development

Ilse Hurbain, Anne-Sophie Macé, Maryse Romao, Elodie Prince, Lucie

Sengmanivong, Laurent Ruel, Renata Basto, Pascal P. Thérond, Graça Raposo, and Gisela D'Angelo 

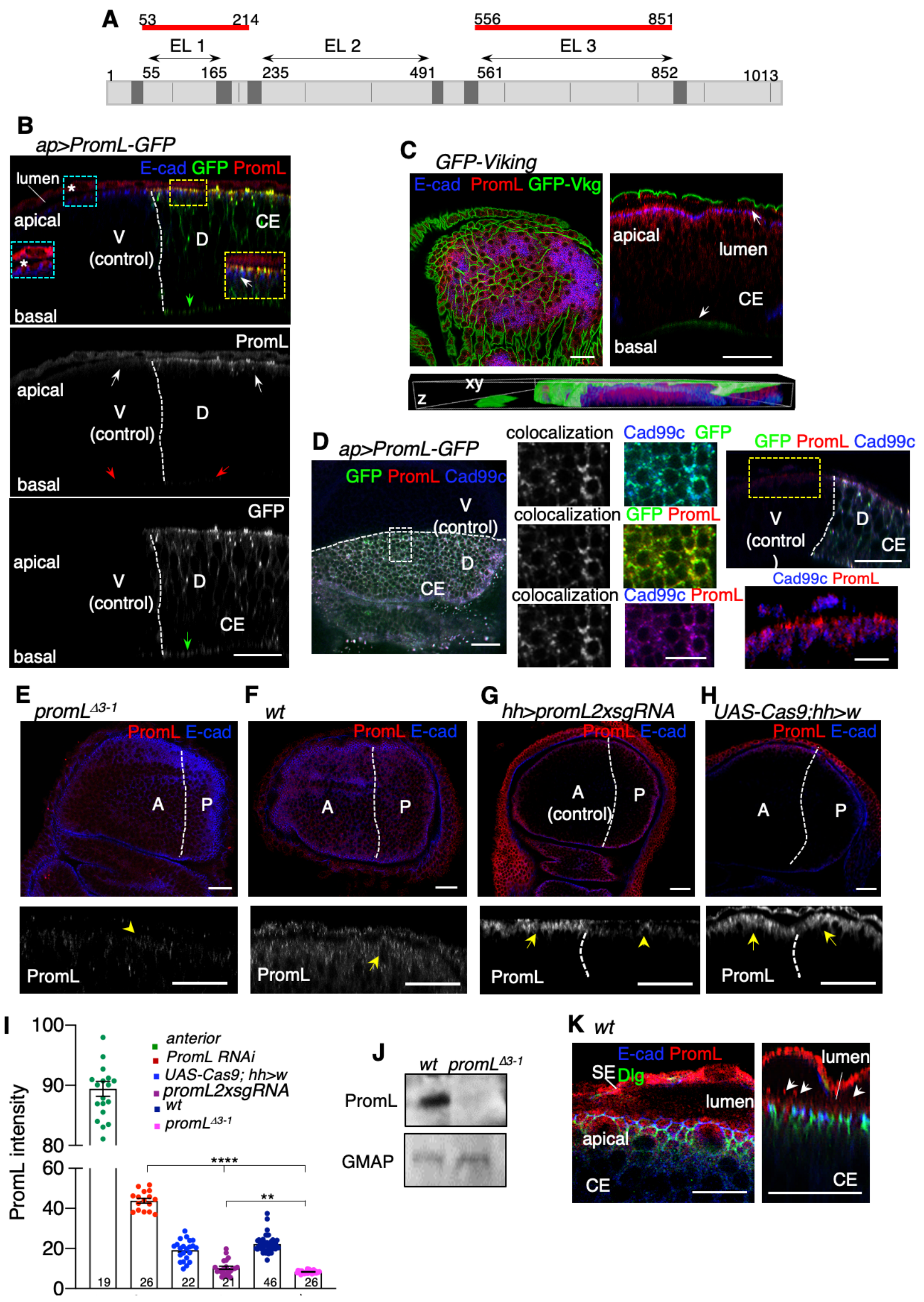

Figure S1. PromL distributes to microvilli of the wing imaginal disc epithelium. Related to Figure 1. (A) Topology of the PromL protein. Dark grey boxes denote the predicted transmembrane 
domains. EL, extracellular loops. Red lines indicate the chosen sequences for the antibody generation. (B-H, K) Transversal and XY confocal single sections of wing imaginal disc of the indicated genotypes stained for GFP (green; white), PromL (red; white), E-cad (blue), Cad99c (blue), and Dlg (green). (B, D, G) The wt compartment ( $\mathrm{V}$ or $\mathrm{A}$ control), allows the comparison between both compartments within the same disc. (B) PromL distributes to the squamous epithelium (asterisk; cyan boxed area), and to the apical surface of columnar cells (CE) (yellow boxed area; white arrows) above the subapical marker Ecad. No PromL signal is detected at the basal pole (red arrows), where a weak PromL-GFP signal ( $9 \%$ of the PromL-GFP signal at the apical) is observed (green arrows). (C) Right: PromL distributes above E-cad and below endogenous Viking protein which labels the basal membrane (arrows). Bottom: 3D volumetric reconstruction (19 plans, spaced $1 \mu \mathrm{m}$ apart). (D) XY and Z-section showing PromL, Cad99c and PromL-GFP distribution at the apical. The high magnification images of the white boxed region in D compartment, where PromL-GFP was overexpressed, show the distribution of the indicated proteins and their colocalization in a XY view (left and right middle panels respectively). In $\mathrm{V}$ and $\mathrm{D}$ compartment Cad99c and PromL distribute to microvilli (magnification of the yellow boxed area of the z-plane view ; right panel). Brightness and contrast were increased for a better visualisation. (E-H) Note the specific dot-like pattern of PromL in wt wing imaginal discs (F) and in control A cells $(\mathbf{G}, \mathbf{H})$ (yellow arrows), and the absence of PromL staining in promL $\Delta^{3-1}$ mutant $(\mathbf{E})$ and in the $\mathrm{P}$ compartment of the conditional mutant promL2xsgRNA (G) (yellow arrowheads). (I) Quantification of PromL intensity in wing imaginal disc of the indicated genotypes. Mean $+/$ - SEM analyzed by unpaired t test $\left({ }^{* * * *} p<0.00001\right)$. The number of discs examined for each genotype is indicated in each column bar. $(\mathbf{J})$ Western blot on wt and promL $\Delta^{3-1}$ wing imaginal discs. Lysates were probed with anti-PromL (this study) and anti-GMAP for loading control. (K) PromL distributed above E-cad and Dlg. The dot-like pattern of PromL (white arrow) at the interface between SE and CE reflects the pseudostratified array of columnar cells, and is compatible with the organization of microvilli at the apical plasma membrane. Dotted lines in (B, D) delimit $V$ and $D$ compartments. Scale bars: $20 \mu \mathrm{m} ; 5 \mu \mathrm{m}$ in magnified images in (D). Images shown in $\mathbf{B}$ and $\mathbf{E}$ are representative of $\mathrm{n}=5$ independent experiments. Images shown in $\mathbf{C}$ and $\mathbf{D}$ are representative of $n=3$ independent experiments. 

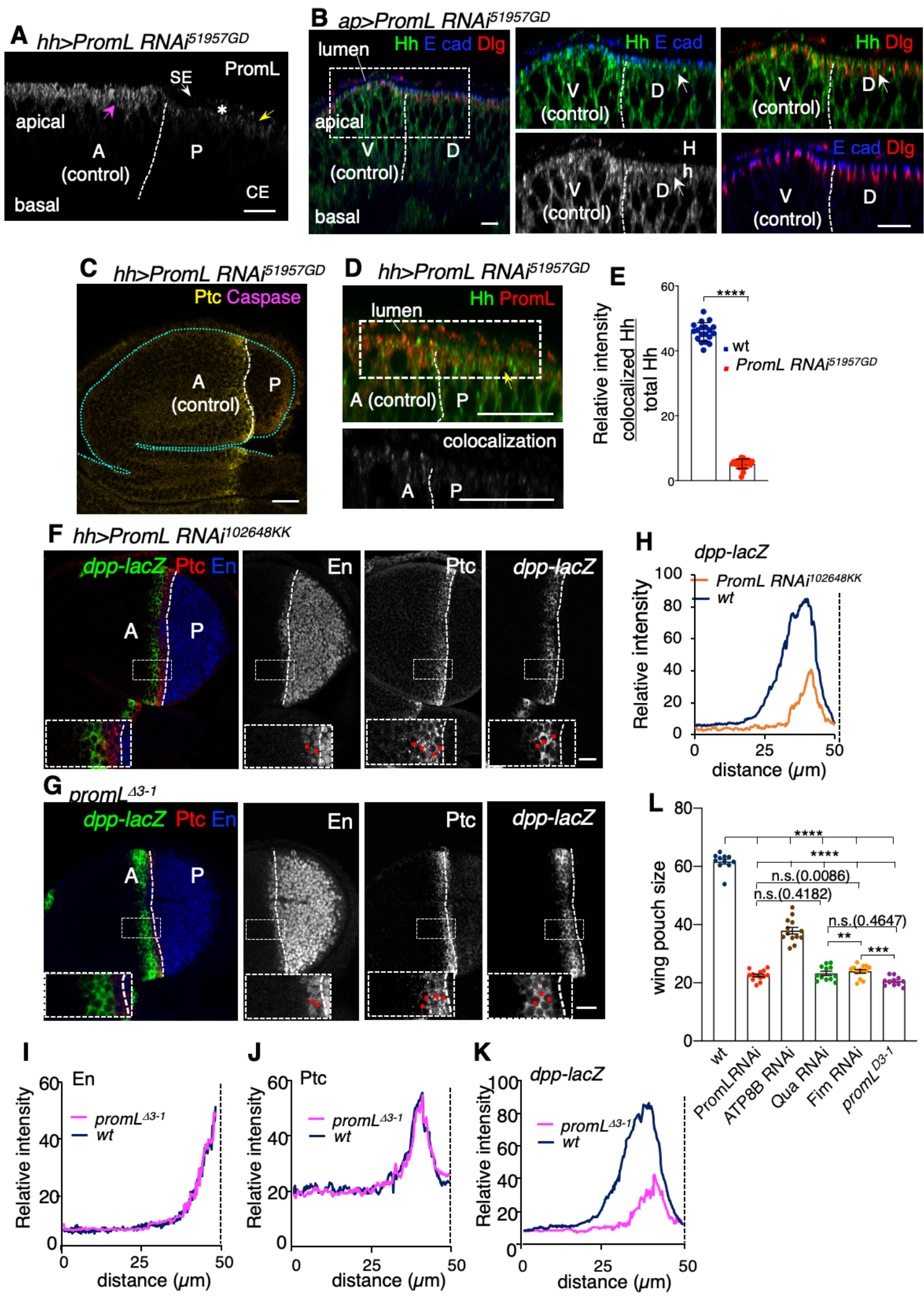

Figure S2. Effects of PromL depletion. Related to Figures 1-3. (A-D, F, G) Confocal images of discs of the indicated genotypes stained for PromL (white), Hh (green; white), E-cad (blue), Dlg 
(red), Caspase III (magenta, Ptc (yellow; red; white), En (blue; white) and for $\beta$-gal (reflecting the expression of the reporter gene dpp-lacZ; green; white). (A) Note the specific dot-like pattern of PromL in A control cells (magenta arrow), and the absence of PromL staining in P depleted cells (yellow arrow). The lumen is indicated by an asterisk. CE, columnar epithelium; SE squamous epithelium. (B) In D cells, $\mathrm{Hh}$ distributed at the basolateral, below E-cad, at the level of Dlg (white arrows). The distribution of Ecad and Dlg is not affected upon PromL depletion (compare V/D compartment). (C) Note that apoptosis levels were not increased upon PromL depletion, indicating and absence of tissue stress. (D) Distribution of $\mathrm{Hh}$, and PromL in $h h>$ PromL RNAi ${ }^{51957 G D}$ discs showing their colocalization. (E) Quantification of $\mathrm{Hh}$ intensity in the colocalization region over the total Hh intensity (see methods). Mean \pm SEM analyzed by unpaired $t$ test $\left({ }^{* * * *} p<0.0001\right)$ (n=24 uppermost apical regions, 8 discs). (F, G) Confocal XY single sections of discs from the indicated genotypes showing $\mathrm{Hh}$ target gene expression. Depletion of PromL triggers a decrease in the range of cells expressing $d p p$, reducing it to 3-4 cells. The short-range targets En and Ptc are not changed. Red dots in the inserts depict the number of cells expressing En, Ptc and $d p p$ (see Table 1, and compare to wt disc in Fig 1J). (H-K) Quantification of $d p p(\mathbf{H}, \mathbf{K})$ En (I), and Ptc (J) intensity plotted as a function of distance from A/P boundary representative for all examined discs ( $w t \mathrm{n}=8$; PromL RNA; $i^{51957 G D} \mathrm{n}=6$ ). (L) Graph reporting the size of the wing pouch size of the discs of the indicated genotypes. Mean \pm SEM analyzed by unpaired $t$ test $\left.{ }^{* * * *} p<0.0001\right)$. Broken lines delimit the A/P compartments. Scale bar: $10 \mu \mathrm{m}$. 

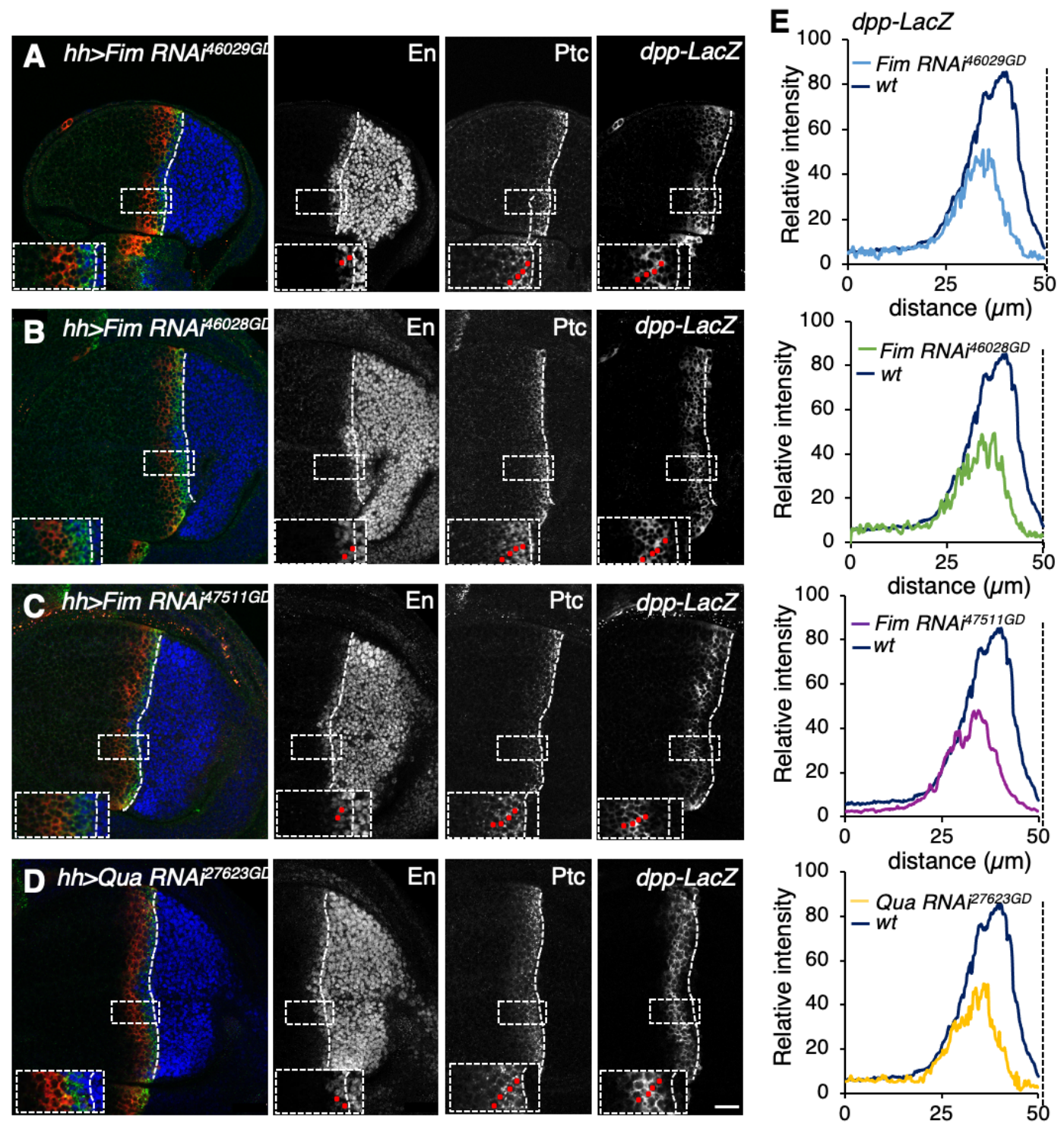

\section{$\mathbf{F}$}

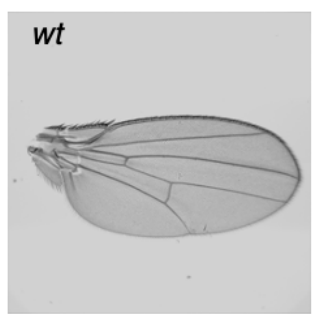

$h h>$ Qua RNAi100856KK

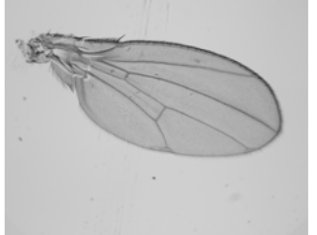

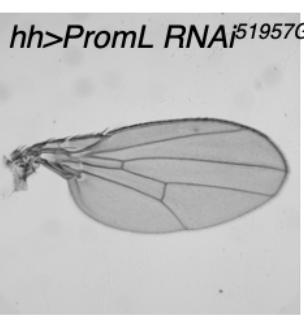

hh>Fim RNA ${ }^{47514 G D}$

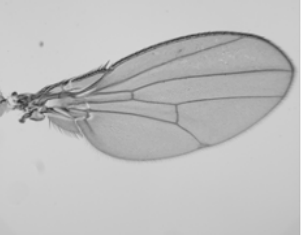

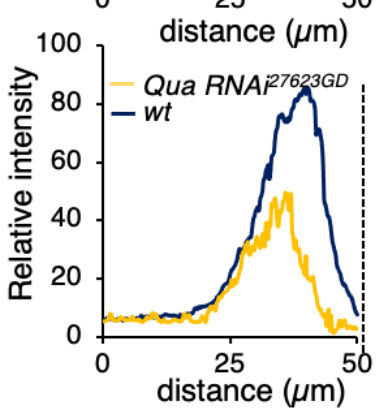

G
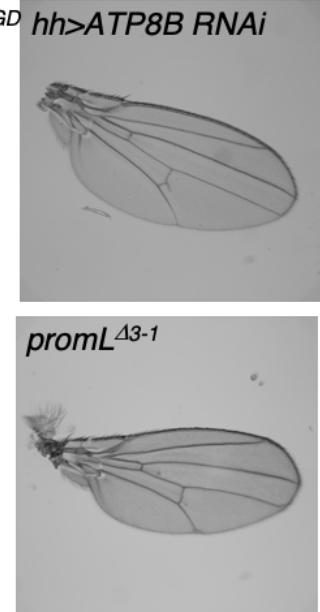

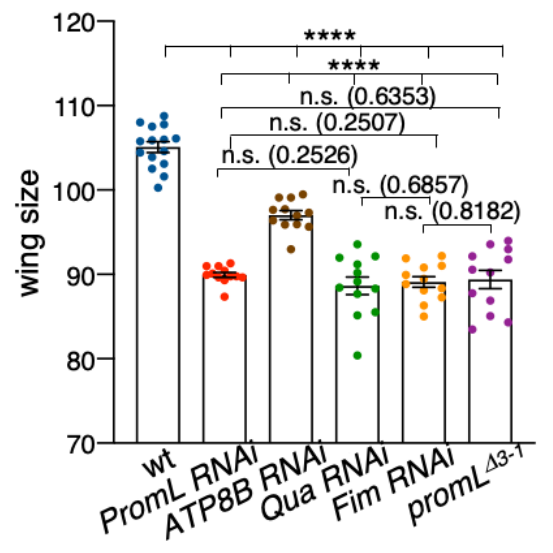

Figure S3. Disruption of microvilli integrity reduces long- but not short-Hh target gene expression. Related to Figures 1-3. (A-D) XY single confocal sections of discs of the indicated 
genotypes stained for En (blue; white), Ptc (green; white), and $\beta$-gal (red; white). Insets depict the number of cells expressing En, Ptc and $d p p$-lacZ. Note the decrease in the range of cells expressing $d p p$ in all genotypes as compared to wt (Figure 1J, Table 1). No changes are observed for En and Ptc. Red dots in the insects indicate the number of cells. Broken lines delimit the A/P compartments. (E) Quantification of $d p p$ intensity plotted as a function of distance from A/P boundary representative for all examined discs (between 6 - 8 discs). (F) Adult wings of the indicated genotypes. (G) Histogram reporting the size of the adult wings. Mean \pm SEM analyzed by unpaired $t$ test (n.s., not significant), ( $n=$ $12-15$ adult wings). Broken lines delimit the A/P compartment. Scale bars: $20 \mu \mathrm{m}$. 


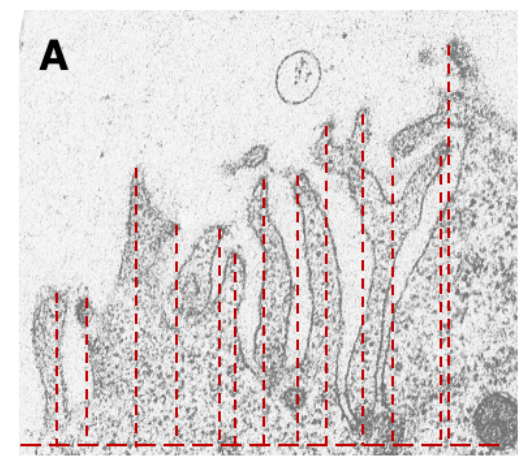

C

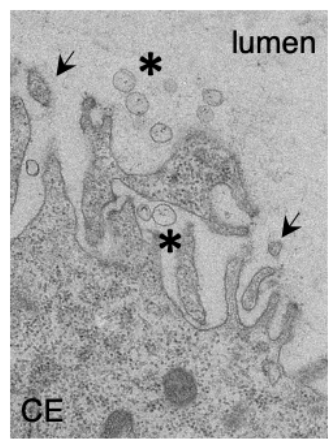

D
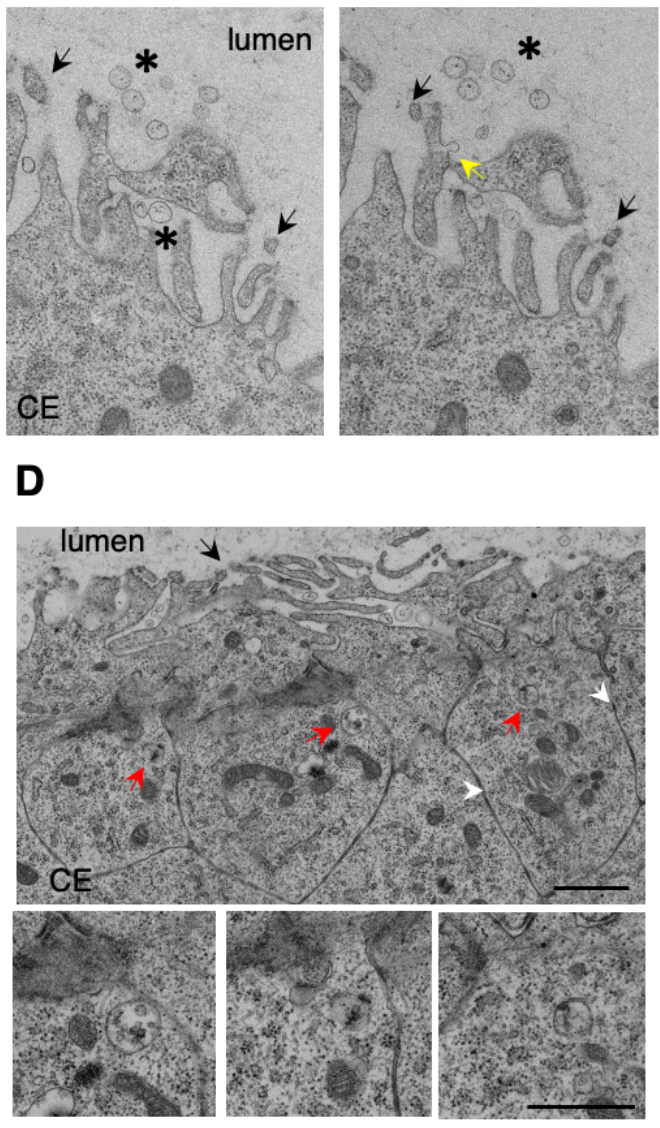
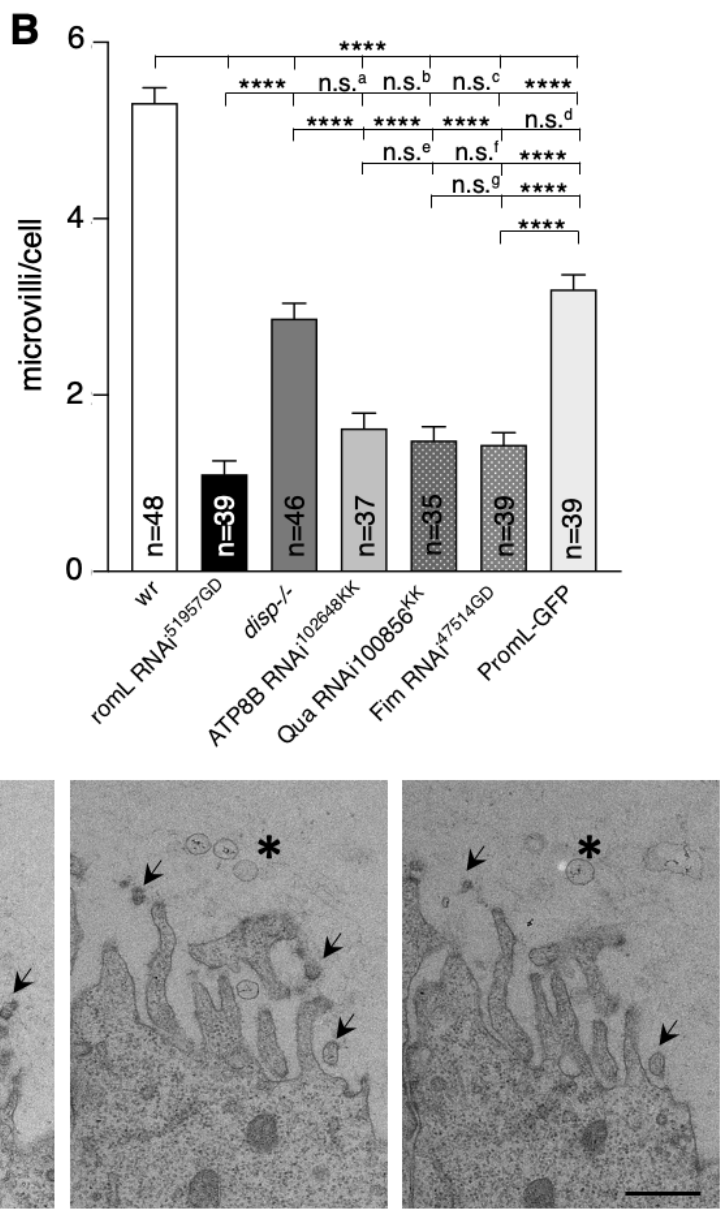

E

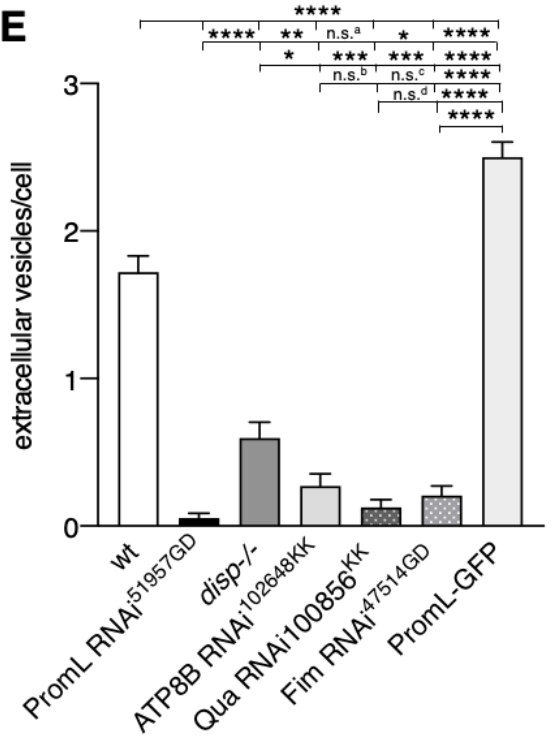

Figure S4. Ultrastructure of the wing imaginal disc epithelium. Related to Figures 1- 4. (A) The length of microvilli was measured by drawing a perpendicular line from their tip to the planar cell surface with an angle of $90^{\circ}$ as illustrated in the cartoon. (B) Graph showing the number of microvilli / cell for the indicated genotypes. Mean \pm SEM analyzed by unpaired $t$ test ${ }^{\star \star * *} p<0.0001$, n.s., not significant; from n.s a-n.s. ${ }^{9}$.: 0.0269; 0.0812;0.1050;0.2724; 0.5647;0.4023; 0.8096. The number of cells counted for each genotype is indicated in each column bars. (C, D) TEM micrograph of a wt wing 
disc showing (C) serial sections of $65 \mathrm{~nm}$ thickness ( $260 \mathrm{~nm}$ total). Asterisk indicate free EVs within the lumen. Note that EVs are less electron dense than fragmented microvilli (arrows), and a bud at microvilli (yellow arrow). (C, D) Arrows point to microvilli, white arrowheads to basolateral junctions, red arrows to MVBs, magnified in lower panels. CE, columnar epithelium. Scale bar: $1 \mu \mathrm{m}$ (D); $200 \mathrm{~nm}$ (C). (E) Graph reporting the number of EVs / cell for the indicated genotypes. Mean \pm SEM analyzed by unpaired $t$ test ${ }^{* * * *} p<0.0001$, n.s., not significant; from n.s ${ }^{a}$-n.s. ${ }^{d} .: 0.2265 ; 0.1400 ; 0.5391 ; 0.3432 ; 0.5647 .50-$ 60 cells were counted for each genotype. 

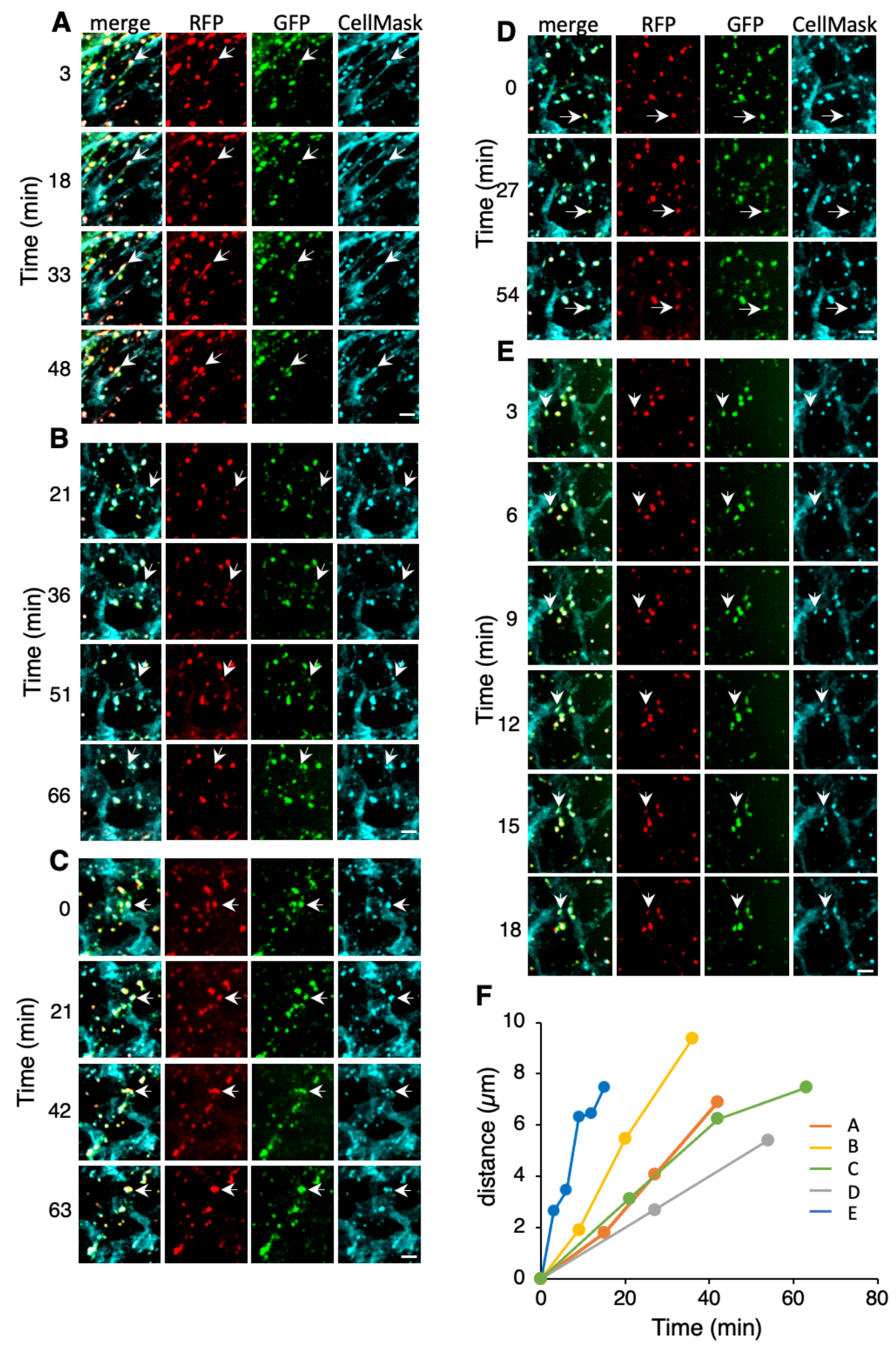

Figure S5. Hh-PromL vesicles travel across the wing disc epithelium. Related to Figure 5. (A-E) Frames from of $h h>H h-R F P$; PromL-GFP discs imaged at $1 \mu \mathrm{m}$ intervals every $3 \mathrm{~min}$, showing additional examples of $\mathrm{Hh} /$ PromL-EV movement in the A compartment. PromL-GFP (green), Hh-RFP (red) and plasma membrane (Cell Mask; Cyan). Arrows depict the EVs. Scale bar: $5 \mu \mathrm{m}$. (F) The distances traveled by Hh/PromL-EV from panels (A-E) were linearly fitted. Note that the distance gradually increased with time. 

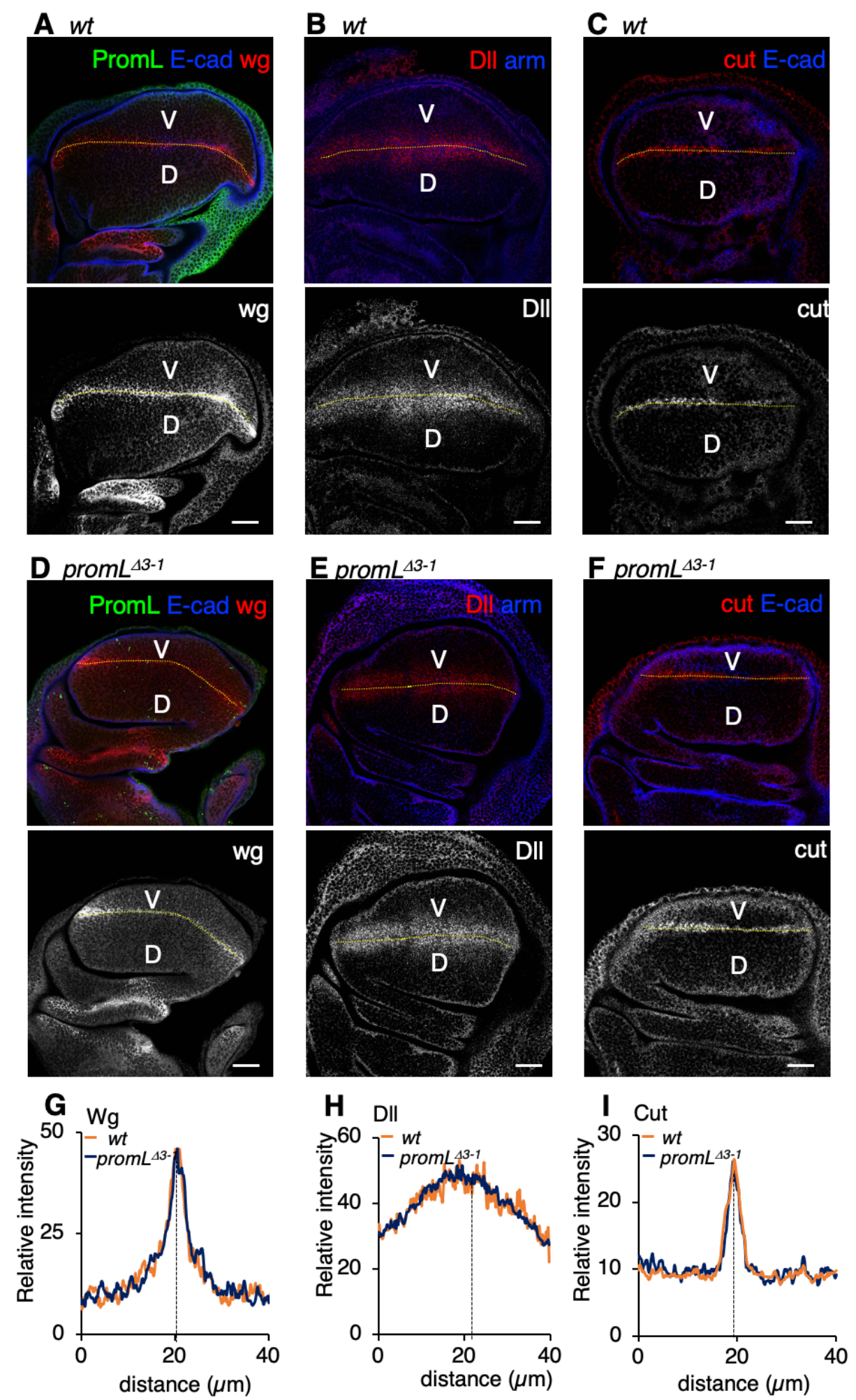

Figure S6. Microvilli integrity does not alter $\mathrm{Wg}$ signaling in the wing imaginal disc. (AF) XY single confocal sections of wt (A-C) or promL ${ }^{\Delta 3-1}$ mutant discs (D-F) stained for Wg (red; white), PromL (green), E-cad (blue), arm (blue), DIl (red; white), cut (red; white). (G-H) Quantification of $\mathrm{Wg}(\mathbf{G})$, DII (H) and Cut (I) intensity plotted as a function of distance from V/D boundary representative for all examined discs (between 6 - 8 discs). No changes are observed for $\mathrm{Wg}$, DII and cut expression in both genetic backgrounds. Dotted yellow lines delimit the V/D compartment. Scale bars: $20 \mu \mathrm{m}$. 